\title{
BIBLIOGRAFIA
}

\section{Bibliografía de y sobre Leopoldo Lugones}

Con motivo de la muerte de Leopoldo Lugones escribió Jorge Luis Borges: "Decir que ha muerto el primer escritor de nuestra República, decir que ha muerto el primer escritor de nuestro idioma, es decir la estricta verdad y es decir muy poco". ${ }^{1}$ Borges ha destacado con reiteración la trascendencia nacional e internacional de Lugones, especialmente el influjo de su arte en la literatura posterior de Hispanoamérica Críticos de las nuevas promociones argentinas (Ara, Ghiano, Jitrik, entre los más notorios) han contribuido con importantes estudios sobre su obra. En Estados Unidos de Norteamérica se han escrito tesis y ensayos valiosos. Revistas y diarios (Babel, Nosotros, Repertorio Americano, La Nación, de Buenos Aires) le han dedicado números de homenaje. Pocas son las revistas hispánicas de este siglo, las antologías y las historias de nuestra literatura en las que no nos sea dable hallar el nombre, selección de la obra y juicios valorativos de esta figura cumbre del modernismo hispanoamericano. No obstante, el acceso a la obra total de Lugones es, hoy por hoy, poco menos que imposible. Ni tenemos una edición de sus obras completas, ${ }^{2}$ ni existe una bibliografía ${ }^{3}$ que registre todos los aspectos de su producción. A llenar en parte ese vacío se encamina esta primera contribución nuestra.

La bibliografía que aquí se publica no es completa ni perfecta.

1 Jorge Luis Borges, Leopoldo Lugones (Buenos Aires: Ediciones Troquel, 1955 , p. 81). [Publicado antes en Nosotros; véase Núms. 1 y 141].

En 1938 el diputado Pío Pandolfo presentó al Congreso un proyecto de ley en este sentido (La. Nación, 20-5-1938).

3 Sabemos que el Instituto de Literatura Argentina de la Universidad de Buenos Aires ha encomendado a los señores Lermón y Kisnerman la preparación de la tan deseada bibliografía lugoniana, cuya publicación podrá satisfacer el deseo varias veces expresado a quienes fuimos sus alumnos por el ilustre creador de dicho Instituto, Dr. Ricardo Rojas. 
En realidad es una selección de una cronobibliografía de Leopoldo Lugones que hemos venido preparando durante varios años. La índole de esta revista y el deseo de no repetir han dictado las limitaciones que fácilmente comprobará el lector. Nuestro propósito ha sido, en primer término, dar la ficha exacta de todas las obras de Lugones, en sus diversas ediciones, publicadas en forma de libro o folleto, mas todos los trabajos de información y crítica sobre su personalidad humana y de escritor que ha llegado a nuestro conocimiento. Hemos consultado las bibliografías fundamentales que sirven de guía para este tipo de trabajos, y hemos visto la gran mayoría de las obras y revistas que se citan. En nuestro acopio de datos nos han sido particularmente útiles el libro de Raúl Pultera (h), Lugones... (Buenos Aires, I956) y la recopilación de Sturgis Leavitt (con la colaboración de Madaline W. Nichols y Jefferson Rea Spell), Revistas bispanoamericanas. Indice bibliográfico: 1843-1935 (Santiago de Chile: Fondo Histórico y Bibliográfico José Toribio Medina, I960). A estas obras remitimos al investigador que quiera conocer todo lo referente a la actuación pública, la evolución ideológica ${ }^{4}$ y la mayor parte de las publicaciones periodísticas de Lugones no recogidas en libro ni mencionadas por nosotros. En el valioso y preciso volumen de Leavitt se hallarán también los títulos de poesías y prosas que Lugones publicó en revistas y diarios antes de incluirlas en los libros correspondientes. En la biografía de Leopoldo Lugones (h), Mi padre (Buenos Aires: Ediciones Centurión, 1949) se encontrarán referencias a la iniciación periodística y literaria del Lugones juvenil, que aquí no registramos.

La vasta y variada labor de Lugones dispersa en diarios y revistas constituye, indudablemente, un aspecto muy importante de su obra. En ella está el Lugones cotidiano - hombre, pensador, artista-en los diferentes perfiles de su personalidad cambiante. En esta parte de su obra se puede seguir, acaso en forma más evidente y acusada que en sus libros, la evolución de su pensar y de su sentir., Es posible que allí esté también mejor expresada la unidad interna de una realidad que a primera vista of rece tantas contradicciones. Pero si esos diarios testimonios de un alma a todas luces compleja resultan valiosos como documentación exhaustiva del Lugones total, no son imprescindibles para una valoración preferentemente estética. De ahí la necesidad de una selección, que es lo que aquí hacemos. Según este criterio, sólo anotamos

4 Véase Guillermo Ara, "Leopoldo Lugones, hombre de ideas", en Cursos y Conferencias, Buenos Aires, 1958, LIII, Núm. 283, pp. 238-257, 
un limitado número de artículos con los cuales se puede saber lo que nuestro autor pensaba acerca de escritores argentinos e hispanoamericanos de su tiempo, y sobre estética en general, literatura y lenguaje.

Aclaración similar debemos hacer con respecto a la bibliografía sobre Leopoldo Lugones. Si bien consignamos cuanto título firmado nos ha sido posible conocer, hemos descartado la mayor parte de las notas u otras referencias anónimas que dan noticia de la actuación de Lugones en los variados campos de su actividad, así como la multitud de menciones, homenajes y todo otro tributo con que fue honrado en vida o después de su muerte. Asimismo hemos restringido nuestra mención de antologías, historias literarias u otras publicaciones de carácter general a las que hemos considerado que, en mayor o menor grado, significaton una aportación. En esto, como en todo lo que no es histórica y científicamente objetivo, nos hacemos responsables de nuestro personal criterio, falible como cualquier otro. Sírvannos de escudo y justificación la nobleza de nuestro intento y la dedicación que ha presidido nuestro trabajo.

Por último, lamentamos no haber podido recurrir al archivo de Leopoldo Lugones, actualmente en poder de su hijo. Quien tenga la suerte de contar con esta fuente documental podrá llenar en lo futuro los huecos que aquí se encontratán.

\section{Alfredo A. Roggiano}

State University of Iowa

\section{Bibliografía dE LEOPOLDO LUGONES}

\section{A. Libros y Folietos}

I. Los mundos [poema] (Córdoba: Imprenta "La Velocidad", de F. Domenici, r893) [Folleto reproducido, bajo el título de "Ia primera obra de Lugones", en Nosotros. Número extraordinario dedicado a Leopoldo Lugones. Segunda Epoca. Año II*. Tomo VII. Núm. 26-28. Mayo-julio de I938, págs. I65-I74. También en Leopoldo Lugones (h), Mi padre (Buenos Aires: Ediciones Centurión, I949, págs. 64-7r)].

* En la carátula dice año III. 
2. Las montañas del oro. Poema. Tiene tres ciclos $i$ dos reposorios, i lo bizo Leopoldo Lugones en M.DCCC.XC.VII (Buenos Aires: Imprenta de Jorge A. Kern, I897), I6o págs.

Las montañas del oro. Poemas. Tiene tres ciclos $i$ dos reposorios, $i$ lo bizo Leopoldo Lugones en M.DCCC.XC.VII Y lo reimprimió con un juicio de Rubén Dario (Montevideo: La "Editorial Rioplatense", I9I9), Ioo págs. [Véase: Darío, Rubén, Núm. 185$]$.

Las Montañas del oro. Poema (Buenos Aires: Editorial Centutión [Colección Eco], I947, III págs. [Nota sobre el autor, viñetas e ilustración de Amilcar Mendoza].

3. Homenaje a la memoria de Emilio Zola. Discurso pnomunciado en el Teatro Victoria de Buenos Aires, el 22 de octubre de 1902 (Buenos Aires: sin pie de imprenta, r902), 24 págs.

Emilio Zola (Buenos Aires: Publicación del Círculo Médico Argentino y Centro Estudiantes de Medicina, I920), 30 págs.

4. Conferencia politica. Discurso pronunciado en el Teatro Victoria, de Buenos Aires, el 6 de noviembre, 1903 (Buenos Aires: Imprenta de Juan Grant e Hijo, I903), 3 I págs.

5. Conferencia (Buenos Aires: Centro Intelectual, tipografía de J. Maggiolo, s. f. [¿I903?]), I6 págs.

6. La reforma educacional (Un ministro y doce académicos) (Buenos Aires: sin pie de imprenta, I903), I 6 págs. [Contiene un "Apéndice", que es el discurso pronunciado en el Congreso Científico Latino-Americano de Montevideo, el 25 de marzo de I9or].

7. El imperio jesuítico (Ensayo bistórico) (Buenos Aires: Compañía Sudamericana de Billetes de Banco, I904), 332 págs. [Edición ilustrada, con planos y mapas].

El imperio jesuítico (Ensayo bistórico). Segunda edición, corregida y aumentada (Buenos Aires: Editorial A. Moen y Hnos., I907), 289 págs.

El imperio jesuítico (Ensayo bistórico). Tercera edición (Buenos Aires: J. Lajouane y Cía., I908) [Según el catálogo de Lajouane. No la he visto].

El imperio jesuático (Ensayo bistórico) [¿Cuarta edición?] (Buenos Aires: Publicaciones de la Comisión Argentina de Fomen- 
to Inter-Americano. Editorial Pucará. Talleres Gráficos de B.U. Chiessino, Avellaneda, I945), 282 págs. [Presentación gráfica y portada de Rodolfo Castagna].

8. Los crepuisculos del jardin [Poemas] (Buenos Aires: Editorial A. Moen y Hnos., 1905), I99 págs.

Los crepuisculos del jardín (Montevideo: Colección Poética, Arte e Idea, I924), I99 págs. [Edición clandestina; reimpresa en I926].

Los crepuisculos del jardin (Buenos Aires: Editorial BABEL [Biblioteca Argentina de Buenas Ediciones Literarias. Director: Samuel Glusberg. Serie A. Vol. XXXVI], I926), 206 págs.

9. La guerra gaucha (Buenos Aires: Editorial Arnaldo Moen y Hnos., I905), 389 págs.

La guerra gaucha (Buenos Aires: M. Gleizer, Editor, r926), 279 págs.

La guerra gaucba (Buenos Aires: Editorial Peuser, S. A., 1946), 289 págs. [Impresa por Francisco A. Colombo. Litografías originales de Alfredo Guido].

La guerra gaucha (Buenos Aires: Editorial Centurión, I947), 290 págs. [Con 30 dibujos originales de Amilcar Mendoza].

La guerra gaucha. Quinta edición, corregida, anotada y con un vocabulario compuesto por Leopoldo Lugones (h) (Buenos Aires: Editorial Centurión [Colección Ulises], 1948), 313 págs. [Esta edición se reimprime como sexta, séptima y octava ediciones en I950, con las mismas características y sin variantes de texto].

La guerra gaucha. Novena edición, revisada y anotada por Leopoldo Lugones (h) (Buenos Aires: Emecé Editores, S. A., I954), 362 págs. [Illustración de la tapa por Guillermo Buitrago].

Al rastro. Episodio de La guerra gaucha (Buenos Aires: Sociedad de Bibliófilos Argentinos, 1955), 44 págs. [Edición espepecial de roo ejemplares, publicada bajo la dirección de Armando Braun Menéndez, con ilustraciones de Jorge Argerich, que fueron grabadas al aguafuerte y tiradas por Raúl Veroni, en su prensa de mano. Se imprimió en la casa de D. Francisco A. Colombo. Este episodio de La guerra gaucha se reproduce en diversas antologías publicadas en Estados Unidos de Norteamérica]. 
ro. Las fuerzas extrañas [Cuentos] (Buenos Aires: Arnaldo Moen y Hno., editores, I906), $27^{8}$ págs.

Las fuerzas extrañas. Ensayo de una cosmogonia en diez lecciones (Buenos Aires: M. Gleizer, editor [Imprenta A. de Martino], r926), 243 págs. [Con una advertencia del autor].

Las fuerzas extrañas (Buenos Aires: Editorial Centutión [Colección Ulises, I2], I948), I87 págs. [Con palabras liminares de Leopoldo Lugones (h) y viñetas de Amilcar Mendoza].

xx. Lunario sentimental [Poemas] (Buenos Aires: Arnaldo Moen y Hno., editores, I909), 301 págs.

Linario sentimental (Buenos Aires: M. Gleizer, editor, I926), 254 págs.

I2. Oddas seculares (Buenos Aires: Arnaldo Moen y Hno., editores, I910), I54 págs.

Odas seculares. Nueva edición corregida (Buenos Aires: Editorial BABEL. Serie A. Vol. XI, I923), I50 págs.

I3. Didáctica (Buenos Aires: Talleres de Otero y Garcia, I910), 368 págs.

I4. Las limaduras de Hepbaestos. I. Piedras liminares (Buenos Aires: Arnaldo Moen y Hno., editores, I9ro), 240 págs.

15. Las limaduras de Hephaestos. II. Prometeo (Un proscripto del sol) (Buenos Aires: Arnaldo Moen y Hno., editores, I910), 428 págs.

I6. Historia de Sarmiento (Buenos Aires: Otero y Cía., impresores, I9II), 246 págs. [Edición ilustrada].

Historia de Sarmiento (Buenos Aires: El Monitor de la Educación Común [Consejo Nacional de Educación]. Tomo XXXVI. Núm. 459, 3I de marzo de I9II), 285 págs. [Segunda edición ilustrada].

Historia de Sarmiento. Nueva edición revisada por el autor (Buenos Aires: Editorial BABEL, r93r), 20I págs.

Historia de Sarmiento. Cuarta edición (Buenos Aires: Publicaciones de la Comisión Argentina de Fomento Interamericano. Talleres Gráficos de B.U. Chiessino, Avellaneda, I945), 28I págs. [Portada de Rodolfo Castagna].

17. El libro fiel [Poesías] (París: H. Piazza, editeur. Imprenta Melzer, I9I2), 80 págs. 
El libro fiel (París. Casa Editora Franco-Ibero-Americana [Biblioteca Liliput), s. f. [1922], I37 págs. [Lleva un prefacio de Ventura García Caldetón. Véase García Calderón, Ventura, Núm. 230].

18. Elogio de Amegbino (Buenos Aires: Otero y Cía., impresores, I9r5), r47 págs.

I9. El ejército de la Iliadia (Buenos Aires: Otero y Cía., impresores, I9r5), 62 págs. [Conferencia pronunciada en 1908 en el Círculo Militar de Buenos Aires. Edición única y definitiva de 500 ejemplares].

20. Cuentos (Buenos Aires: Ediciones Mínimas [Cuadernos mensuales de ciencia y arte, Núm. 8], r916), 32 págs.

21. El problema feminista (San José de Costa Rica: Imprenta Greñas [Colección Ariel, Núm, 70], I916), 72 págs. [Lleva el estudio de Darío mencionado en 2].

22. El payador. Tomo I: Hijo de la pampa (Buenos Aires: Otero y García, I9I6), 265 págs.

El payador (Buenos Aires: Ediciones Centurión [Colección Arte], I944), 355 págs. [Con 52 dibujos de Alberto Güiraldes, I lámina en colores y 2I ejemplos musicales].

23. Rubén Dario (San José de Costa Rica: Imprenta Alsina [Ediciones "El Convivio", publicadas bajo la dirección de J. García Monge]. Prefacio de Roberto Brenes-Mesén, I9I6), 42 págs. [Discurso leído en el Teatro de la Opera, Buenos Aires, el 2 I de mayo de I9r6, en el homenaje que los intelectuales argentinos tributaron a la memoria de Rubén Dario].

Rubén Dario (Buenos Aires: Ediciones Selectas Americanas [Director: Samuel Glusberg]. Año I. Tomo I., Núm. 9, 19r9), págs. $259-176$.

24. Mi beligerancia (Buenos Aires: Oteto y García, I9I7), 240 págs.

25. El libro de los paisajes [Poesías] (Buenos Aires: Otero y García, I917), 240 págs.

El libro de los paisajes (Buenos Aires: M. Gleizer, editor, 1926), I82 págs. 
26. La torre de Casandrct (Buenos Aires: Talleres Gráficos Editorial Atlántida [Biblioteca Atlántida], I9I9), I82 págs.

27. Las industrias de Atenas (Buenos Aires: Talleres Gráficos Editorial Atlántida [Biblioteca Atlántida], I9r9), II2 págs. [Edición ilustrada].

28. El tamaño del espacio (Ensayo de p'sicología matemática) (Buenos Aires: "El Ateneo". Librería Científica y Literaria de Pedro García, I92I), 5 I págs.

29. El dogma de la obediencia. Historia del dogma (Córdoba, Argentina: Boletin de la Facultad de Derecbo y Ciencias Sociales [Director: Arturo Capdevila]. Año I. Núm. I, I92 I), págs. I-I ro [Sobretiro].

El dogma de la obediencia. Constitución del dogma. Idem. Año I, Núm. 3, I92I, págs. 3-93 [Sobretiro].

El dogma de la obediencia. Discurso preliminar. Idem. Año 4. julio-septiembre de I927, págs. 609-624.

30. Las horas doradas [Poemas] (Buenos Aires: Editorial BABEL. Serie A. Vol. I, I922), I74 págs.

3I. Acción (Buenos Aires: Edición Círculo Tradición Argentina. Imprenta A. de Martino, I923), 96 págs. [Cuatro conferencias pronunciadas en el Teatro del Coliseo, del 6 al I7 de julio de I923].

32. La funesta Helena (Estudios belénicos) (Buenos Aires: Editorial BABEL, I923), 63 págs. ["Con el material de cinco conferencias que di en el Odeón de esta ciudad el año I9I6, se halla formado el presente libro". Contiene: La funesta Helena y versiones del griego, en verso alejandrino, de varios pasajes de la Odisea].

33. Un paladin de la Iliada. Estudio critico sobve el personaje Diomedes (Buenos Aires: Editorial BABEL, I923, I35 págs.

34. Estudios belénicos (1923-1924) (Buenos Aires: Editorial BABEL. Serie A. Vol. V, 1924), 399 págs. Este volumen contiene:

La funesta Helena (Segunda edición); Un paladin de la lliada [Véase 33]; La dama de la Odisea (BABEL, I924); Héctor el domadior (BABEL, I924).

35. Romancero (Buenos Aires: Editorial BABEL. Serie A. Vol. XXV, I924), 217 págs. [Reimpresión de idéntico texto y formato: 1925]. 
Romancero (Buenos Aires: Editorial Espasa-Calpe Argentina [Colección Austral, 232], I94I [Reimpresión: Diciembre de I94I; I943; I945; I949, consideradas como cuarta, quinta, sexta, séptima ediciones, si nos atenemos a las denominaciones de segunda, tercera, cuarta y quinta dadas por Espasa-Calpe Argentina].

36. Cuentos fatales (Buenos Aires: Editorial BABEL. Serie A. Vol. XXIV, I924), I66 págs.

37. Filosofícula (Buenos Aires: Editorial BABEL. Serie A. Vol. XX, 1924), I78 págs. [Reimpresión idéntica del mismo año].

Filosofícula (Buenos Aires: Ediciones Centurión [Colección Ulises, 8], 1948), I64 págs. [Viñetas y dibujo de Amilcar Mendoza].

38. La organización de la paz (Buenos Aires: La Editora Argentina, r925), 98 págs. [Serie de artículos que comenzó a publicar en La Nación de Buenos Aires, el I5 de noviembre de 1924].

39. Elogio de Leonardo (San José de Costa Rica: Ediciones "El Convivio", I925), 44 págs. [Conferencia pronunciada en el Teatro Colón de Buenos Aires, el zo de marzo de rgrg, en celebración del cuarto centenario de Leonardo da Vinci].

40. El ángel de la sombra [Novela] (Buenos Aires: M. Gleizer, editor, 1926), 208 págs. [Con un dibujo de Alejandro Sirio].

4T. Poemas solariegos (Buenos Aires: Editorial BABEL. Serie A. Vol. LV, I928), 208 págs. [Segunda edición: Idem., 1929, 247 págs].

42. Nuevos estudios belénicos (Buenos Aires-Madrid: Biblioteca Argentina de Buenas Ediciones Literarias [BABEL]. Serie A, sin número, 1928$), 247$ págs.

43. La patria fuerte (Buenos Aires: Círculo Militar [Biblioteca del Oficial. Vol. CXXXIXa.]. Taller Gráfico de Luis Bernard, 1930), I 26 págs. [Segunda edición: Editorial BABEL, 1930], 126 págs.

44. La grande Argentina (Buenos Aires: Editorial BABEL, I930), 202 págs.

45. Politica revolucionaria (Buenos Aires: Ediciones Librerías Anaconda, r93I), ro9 págs. 
46. El unico candidato (Buenos Aires: sin pie de imprenta, I931), I3 págs.

47. El estado equitativo (Ensayo sobre la realidad argentina) (Buenos Aires: Editora Argentina, I932), III págs.

48. Romances del Río Seco [Obra póstuma] (Buenos Aires: Sociedad de Bibliófilos Argentinos, 1938), I70 págs. [Esta edición, dirigida por Eduardo J. Bullrich y Carlos M. Mayer, e impresa en la casa de D. Francisco A. Colombo, no salió a la venta, pues el número de ejemplares fue limitado al de los miembros de la Sociedad de Bibliófilos Argentinos].

Romances del Río Seco (Buenos Aires: Francisco A. Colombo, I938), I70 págs. [Se hicieron r,o00 ejemplares numerados, firmados por la señora Juana González de Lugones, para venta al público].

Romances del Río Seco (Buenos Aires: Ediciones Centurión, r948), 2 I I págs. [Edición anotada por Leopoldo Lugones (h), con dibujo de Alberto Güiraldes, como la anterior].

49. Roca [Obra póstuma] (Buenos Aires: Edición de la Comisión Nacional Monumento al Teniente General Julio A. Roca. Casa Editora Coni, 1938), 205 págs. [Lleva prólogo de Octavio R. Amadeo; edición limitada a roo ejemplares de venta prohibida].

50. Palabras en la tumba de Ricardo Güiraldes (San Antonio de Areco, Provincia de Buenos Aires: Imprenta Monserrat, I938).

5I. "Don Segundo Sombra", de Ricardo Güiraldes (San Antonio de Areco: Imprenta de José B. Monserrat, octubre de I939), I6 págs. [Contiene también el Núm. 5r].

52. Diccionario etimológico del castellano usual [Obra póstuma] (Buenos Aires: Edición de la Academia Argentina de Letras. Talleres Gráficos de Guillermo Kraft, T944), 622 págs. [Con "Advertencia" de la Academia].

B. Antologías, Selecciones, Poesías Completas

53. Leopoldo Lugones, Antología (San José de Costa Rica: Edición de J. García Monge [Colección Ariel. Núm. 23] r9r2), 64 págs. 
[Con un retrato de Lugones y una parte del estudio crítico de Rubén Darío].

54. Poesia de Leopoldo Lugones (México: Editorial Cultura, 19r7) [Prólogo de Antonio Castro Leal].

55. Leopoldo Lugones, Selección [Poesías] (Montevideo: M. García [Ediciones Minerva, Núm. I, agosto de I9I9), 40 págs. [Se incluye "Leopoldo Lugones", por Rubén Darío].

56. Leopoldo Lugones, Las montañas del oro. El libro de los paisajes (Poemas selector) (México: Ediciones de El Ateneo Reissig de México. Talleres Gráficos de Heliodoro Barrales, Sucs., x919) [Contiene selecciones de los dos libros que forman el título más otras de Lunario sentimental].

57. Leopoldo Lugones, Antología poética (Madrid: Espasa-Calpe, S. A. [Impreso en Argentina: Colección Austral, 200], I94I), 337 págs. [Selección y próloga de Carlos Obligado].

Segunda edición: Idem: Espasa-Calpe Argentina, I94I.

Tercera edición: Idem: Buenos Aires-México, I942.

Cuarta edición: Idem, I944; Quinta: Idem, 1946; Sexta: Idem, 1947; Séptima: Idem, r949; Octava: Idem, r95r.

58. Obras poéticas completas (Madrid: M. Aguilar editor, 1948), I,475 págs. [Con "Advertencia editorial", un prólogo titulado "La vida y la obra de Leopoldo Lugones", por Pedro Miguel Obligado y un retrato de Leopoldo Lugones por A. Billis, de I9I8].

Obras poéticas completas: Idem., Segunda edición, r952; Tercera edición, 1959.

59. Leopoldo Lugones, Antología de la prosa (Buenos Aires: Editorial Centurión' [Colección Ulises, 15], I949), 509 págs. [Selección y comentario inicial de Leopoldo Lugones $(h)$. Referencias bibliográficas, etc.].

60. Los mejores versos de Leopoldo Lugones (Buenos Aires: Cuadernillos de poesia, 3I, I956).

\section{Artículos, Prólogos y Otras Publicaciones en Periódicos}

[Sobre literatura argentina e hispanoamericana]

6I. [Capdevila, Arturo]. "El poeta y su poesia. Arturo Capdevila", Nac., 30 de enero de 1927; Rep. Amer., XV, 8-Io-I2. 
62. [Darío, Rubén]. Véase Núm. 23; se incluye en Rubén Dario, Poemas escogidos. Seguidos de poemas dispersos (México: Lectura selecta. Tip. Murguia, IgI9).

63. [Díaz, Leopoldo]. [Nota de presentación a "Poemas", de Leopoldo Díaz], Rev. Mod., II, 6r-62.

64. [Franco, Luis]. "Un poeta pagano", Nac, I9 de septiembre de I923; Rep. Amer., VII, I6I-I63.

65. [Güiraldes, Ricardo]. Véase Núms. 50 y 5I; "En el sepelio de Güiraldes", Nac., I6 de noviembre de I927; Ręp. Amer., XV, 378-38I; "Don Segundo Sombra", Atenea, 23 (96), abril I923, 319-325; Rep. Amer., XXVII, 347.

66. [Jaimes Freyre, Ricardo]. "Castalia bárbara", Rev. Mod., II, 338. 34I. [Se incluye como prólogo a Ricardo Jaimes Freyre, Castalia bárbara (Buenos Aires: Imprenta de Schurer-Stolle, I899)].

67. "Literatura argentina", Babel, Núm. 22, febrero de I927.

68. [Mariátegui, José Carlos], "In memoriam" en "Del homenaje argentino a Mariátegui", Vid. Lit., I930; Rep. Amer., XX, 344347; Gac. Lit., Año I, Núm. 3, abril 1956, pág. 6.

69. [Martín Fierro]. "Contestaciones a la encucsta de Martín Fie. rro..." [Contestan Lugones y otros], Mar. F., Núms. 5-6, I5 de mayo-r 5 de junio de r924.

70. [Martínez Estrada, Ezequiel]. "Laureado del Gay Mester", Nac., I8 de agosto de I929.

7r. [Nalé Roxlo, Conrado]. "Albricias poéticas", Nac., I8 de noviembre de I923; Rep. Amer., 333:335. [Se incluye como prólogo a El grillo (Buenos Aires, I923)].

72. [Obligado, Pedro Miguel]. "Pedro Miguel Obligado", Nac., I7 de mayo de I925. [Se incluye como prólogo a $E l$ bilo de oro (Buenos Aires, I924; 4ta. ed., I94I) y a Melancolía (Buenos Aires, I945)].

73. [Olaguíbel, Francisco M. de ]. "Olaguíbel, Francisco M. de, Oro y negro", Rev. Mod., VI, I45-I47.

74. [Peatson, Isaac R.]. "Carta...", en Juicios acerca de la novela argentina de costumbres "El triunfo del siglo", por I saac R. Pearson 
(Imprenta de "La Revista", s. f.), 48 págs. [Juicios de L. Lugones, C. Guido Spano y Claudio R. Pozuelo].

75. [Pedroni, José]. "El hermano Iuminoso", Nac., I5 de junio de 1926. [Sirve de prólogo a Gracia plend (Buenos Aires, I927; Ibid., I929; Ibíd., Santa Fe, I960)].

76. [Rega Molina, Horacio]. "Versos de Horacio Rega Molina", Nac., I5 de noviembre de 1926.

77. [Salaverria, José María]. "Los idólatras" [Objeciones a José María Salaverría acerca del mestizaje argentino. Sobre si la América Hispánica debe llamarse "Hispanoamérica" o "Indoamética". El artículo de Salaverría se publicó en Revista de las Españas, Núms. 22-23, 1928], Rep. Amer., XVII, 358-359 [Tomado de Vid. Lit.].

78. [Sarmiento, Domingo Faustino]. Véase Núm. I6; "La doctrina de Sarmiento", Rep. Amer., XIX, 28I [Tomado de Vid. Lit.; Razones para un mayor contacto entre Argentina y Estados Unidos de Norteamérica].

79. [Tablada, José Juan]. "J. J. Tablada", prólogo al libro de este autor titulado Al sol y bajo la luna (México, 1918).

80. [Torres Bodet, Jaime]. "El ftaude piadoso", Rep. Amer., XV, 242-243 [Aclaración y protesta con motivo de una cita de Lugones hecha por Torres Bodet].

[Sobre ideas estéticas, literarias y lenguaje]

8I. "La educación artística", Nac., 24 de abril de I905.

82. "Una página de estética", Nac., I3 de julio de I924; Rep. Amer., IX, II3-II5.

83. "Nuestras ideas estéticas", Rev. Inst. Parag., Año X. Núm. 62, $833-846$.

84. "La anarquía estética", Nac., 8 de septiembre de r929.

85. "La redención por la belleza" [sobre Beethoven], Rep. Amer., $\mathrm{XV}, 32 \mathrm{I}-324$.

86. "Encuesta sobre la mala literatura", $R d z ., 2$ de mayo de $I 923$.

87. "Arte y cultura" [artículo póstumo], Nac., 20 de marzo de 1938.

88. "Prólogo de Lunario sentimental", Rev. Mod., XIII, 268-27I. [Véase Núm. II]. 
89. "Situación del lector", en Pedro Juan Vignale y "César Tiempo", Exposición de la actual poesía argentina: $1922-1927$ (Buenos Aires. Editorial Minerva, 1927), págs. I-II.

90. "El secreto de Don Juan", Rep. Amer., VII, Ioo-Io4.

9r. "Dos ilustres lunáticos o la divergencia universal" [sobre Hamlet y Don Quijote], Rev. Mod., XV, I88-r92. [Véase II, págs. 2072 I 7 y 58, pág. 3I3 ss.].

92. "Significación de Goethe", Rep. Amer., XXIV, 305 y 3I0-3II.

93. "La catedral muerta" [la de Reims], Nac., I6 de septiembre de I92I; Rep. Amer., III, I9I-I94; Rev. Univ. Hond., XII, 551-558; A. Hond., III, I089-1096.

94. "El espíritu del Renacimiento", Rev. Mod., XII, 256.

95. "El alma de la tragedia", Nac., 23 de julio de r932; Rep. Amer., $\mathrm{V}, 83-85$.

96. "Emilio Zola" [su ideología y su técnica], Rep. Amer., VIII, 289293. [Véase Núm. 3].

97. "La lengua que hablamos", Cu. Ven., XLV, 212-2I5.

98. "El lenguaje pobre", Rep. Amer., XXVIII, I57.

\section{BIBLIOGRAFIA SOBRE LEOPOLDO LUGONES}

\section{A}

99. Abril, Xavier, "La evolución de la poesía moderna", CCLC., Núm. I9, julio-agosto de 1956, págs. I3I-I48.

- Antologia de la poesía modema bispanoamericana (Montevideo: Cuadernos "Julio Herrera y Reissig", Núm. 46, s. f. [¿土958?], págs. 7־9.

100. Acevedo Díaz (h), Eduardo, "Los centauros" [sobre La guerra gaucha], en Los nuestros (Estudios de critica) (Buenos Aires: Edición Martín García, I9I0), págs. I62-200.

IoI. Acuña, Angel, Ensayos (Primera serie) (Buenos Aires: Edición Espiasse y Cía., I926), págs. т2I-I30.

102. Aíta, Antonio, "Notas al margen de la poesía argentina", Nos., Año XXIII, T. 63, Núms. 236-237, enero-febrero de I929, págs. I 8-29. 
—- La literatura argentina contemporánea, x900-1930 (Buenos Aires: J. L. Rosso, I93I).

I03. Albareda, Ginés de y Garfias, Francisco, Antología de la poesía bispranoamericana. Argentina (Madrid: Biblioteca Nueva, 1954), págs. 38-39 y 283-300.

104. Alegría, Fernando, Walt Whitman en Hispanoamérica (México: Ediciones Studium, I954), págs. 265-275.

I05. Amadeo, Octavio R., "Leopoldo Lugones", Nac., 8 de agosto de 1938.

- , Prólogo a Roca. [Véase Núm. 49 sobre Roca; véase también la revista Sol y Lana, Buenos Aires, Núm. 2, 1939, pág. I 63$]$.

- Doce argentinos (Buenos Aires: Editorial Cimera, I945 [Prólogo de Angel Acuña]), págs. I8I-I99.

106. Anderson Imbert, Enrique, Historia de la literatura bispanoamericanct (México: Fondo de Cultura Económica; Ira. ed., I954), págs. 2I8-220; 2da. ed., Idem., I957, págs. 276-279; 3ra. ed., I96I; Vol. I, págs. 374-380.

- y Kiddle, Lawrence B., Veinte cuentos hispanoamericanos (New York: Appleton-Century-Crofts, Inc., 1956), págs. 1727 [se incluye el cuento "Yzur"].

ro7. Anónimo, "Leopoldo Lugones", Rep. Amer., I, 50-5I [De Ideas]. _-, "Con Leopoldo Lugones" [entrevista], Rep. Amer., II, 240$24 \mathrm{~T}$.

-, "La reforma educacional, por Leopoldo Lugones", Nac., 2 de mayo de I903.

—_- "Los crepuisculos del jardin", Nac., 9 de junio de I905.

__, "La guerta gaucha, por Leopoldo Lugones", Nac., 5 de noviembre de 1905.

—_, "El imperio jesuítico", Nac., I4 de abril de r908.

—., "Prometeo", Nac., to de septiembre de Igro.

—_, "Didáctica", Nac., 6 de febrero de IgIr.

_- "La influencia de Lugones sobre Villaespesa, según lo hace notar Entique Díez-Canedo en La Lectura, Madrid", Coj. Ilust., XVII, 457-458.

- "El libro de los paisajes", Nac., I2 de diciembre de 1916. —_, "Mi beligerancia", CyC.. I3 de octubre de I9r7: 
—_, "Bibliographical data" [a propósito de una colaboración de Lugones], Int. Amer., diciembre de I920, pág. 72.

-, "Filosofícula, por Leopoldo Lugones", Nac., Is de junio de I924.

-, "Romancero, por Leopoldo Lugones", Nac., 9 de noviembre de I924.

_-, "Artistas y literatos argentinos solicitan un premio para Lugones" [Más de cincuenta importantes escritores argentinos piden para Lugones el premio nacional de literatura de I924], Rep. Amer., IX, 235.

—_, "Historia de Sarmiento, por Leopoldo Lugones", Nac., I7 de septiembre de r93r.

- _, "Romances del Río Seco, por Leopoldo Lugones", Nac., 30 de abril de I938.

—_, "Roca, por Leopoldo Lugones", Nic., i2 de febrero de I939.

-_, "En memoria de Lugones", Nac,, 20 de febrero de I945.

nes", Nac., 20 de febtero de I945.

—, "El imperio jesuítico, por Leopoldo Lugones", LaPr., 23 de junio de r946.

I08. Antuña, José G., "Leopoldo Lugones", en Litterae. Ensayos de critica. Comentarios (París: Imprimerie Artistique A. Fabte [Casa Editora Franco-Americana], I926), págs. 9-72.

109. Anzoátegui, Ignacio B., "Lugones, el poeta de la patria", Nac., I 8 de abril de I944.

I ro. Ara, Guillermo, Leopoldo Lugones. La etapa modernista (Buenos Aires: Industrias Gráficas Aeronáuticas, I955).

-, Leopoldo Lugones (Buenos Aires: Editorial "La Mandrágora", I958).

_- "Leopoldo Lugones, hombre de ideas", Cur. Conf., I958, LIII, Núm. 283, págs. 238-257.

III. Arana, Z. V., La conferencia de Lugones en el Jockey Club. Panegirico de Caligula, Claudio y Nerón (Buenos Aires: Establecimiento Gráfico "La Palma", r922).

$\therefore$. . "Lugones al máximo", en Desinflando globos (Buenos Aires: E. Bayardo, 1923), págs. 5-73. 
I1 2. Araquistain, Luis, "Sobre las dictaduras. Entre Lugones y Araquistain" [Explicación de Araquistain sobre un párrafo que ofendió a Lugones. Véase Leavitt, Núm. 5I2], Rep. Amer., XIV, págs. $269-270$.

Ir3. Araujo Herrera, G., Antología lirica de poesiads recitables. 34 grandes poetas. 50 composiciones magistrales (Buenos Aires: Segunda edición. Editorial Araujo [Colección Programa], r944).

Ir4. Arciniegas, Germán, The Green Continent. A Comprebensive View of Latin America by Its Leading Writers. Selected and edited by ... Translated from Spanish and Portuguese by Harriet de Onis and Others (New York: A. A. Knopf, 1944), págs. 339-353.

I15. Arrieta, Rafael Alberto, "La Voz", Nos. [cit. en Núm. I], págs. 49-50.

- , "Leopoldo Lugones, profesor", La Pr., I9 de octubre de I94ז.

-_, "Leopoldo Lugones profesor y helenista", Dav., Núm. 5r, marzo-abril de 1954, págs. 20-26.

-, Introducción al modernismo literario (Buenos Aires: Columba, 1956), págs. 45-48.

I16. Arslan, Emir Emin, "Una carta de Lugones", Not, III, Núm. I13, 6 de octubre de 1957.

—_. "Mi beligerancia, de Leopoldo Lugones", Not., III, Núm. I6, 27 de octubre de I9I7.

-_-, "Lugones, la evolución de sus ideas políticas, sus estudios de etimología arábiga, su traducción de La Ilia ada", Nac., 3 de julio de 1927.

I17. Aubrun, Charles, Histoire des lettres bispano-américaines (París: Librairie Armand Colin [Collection Armand Colin, 291], 1954), págs. I85-186.

Ix8. Babel [Revista dirigida por Samuel Glusberg]. Segunda Epoca: Buenos Aires, Núm. I9, mayo de 1926 [Número dedicado a Leopoldo Lugones, con colaboraciones de Rafael Barrios, Nicolás Coronado, Baldomero Fernández Moreno, Ventura García Calde- 
rón, Alberto Gerchunoff, Roberto F. Giusti, Samuel Glusberg, Amador L. Lucero, Gabriela Mistral, José Pereira Rodríguez y José Vasconcelos].

I I9. Bajarlía, Juan J., Literatura de vanguandid (Buenos Aires: Editorial Araujo [Colección Universal], r946), págs. 9I-96.

x20. Barbagelata, Hugo David, "Víctor Hugo y la América Latina", en Rev. Nac., I925, Núm. I66 [Hay sobretiro].

- La novela y el cuento de Hispanoamérica (Montevideo: Talleres Gráficos de Enrique Míguez y Cía., I947), págs. 84-85.

I2r. Barleta, Leonidas, "La Grande Argentina de Lugones", Vang., I9 de octubre de 1930.

r22. Barrantes Molina, Luis, "Otros errores de Leopoldo Lugones", El pueblo, 23 de octubre de 1936.

I23. Barreda, Ernesto Mario, "Escorzo de Lugones", Nos. [cit. en I], págs. 209-2I2.

- Nuestro parnaso. Colección de poesias argentinas (Buenos Aires: J. L. Dasso y Cía,, editores [1944]), Vol. III, pág. 221.

124. Barret, Rafael, "Rimas de Lugones: Lunario sentimental", en Al margen. Criticas literarias y científicas (Montevideo: O. N. Bertani, r9r2), págs. I5-T9.

I25. Barrios, Rafael [Véase Núm. II8].

I26. Bartholomew, Roy, Cien poesias rioplatenses (1800-1950) (Buenos Aires: Editorial Raigal, I954), págs. I45-I72.

127. Bartolini, Domenico [Direttore generale], Enciclopedia Italiana (Roma: Instituto Poligrafico Dello Stato, r957), Vol. VII, pág. I62.

I 28. Bazin, Robert, Historia de la literatura americana en lengua española. Traducción de Josefina A. de Vázquez. Edición, noticia preliminar y notas complementarias al cuidado de Raúl H. Castagnino (Buenos Aires: Editorial Nova, I958], págs. 338-34I.

I29. Beltrán, Oscar R., Historia de la literatura bispanoamericana (Buenos Aires: Manuel Tato, editor, I938), pág. 324.

r3o. Bellini, Giusseppe, La poesia modernista. Formazione e sviluppo (Milano: La Goliardica, s. f.). 
_- La poesia del modernismo (Milano: La Goliardica, I956).

- La letteratura ispano-americana. I. Dalle origini al modernismo (Milano: La Goliardica, I959), págs. I36-139.

—, [Véase también Gallo, Ugo y Bellini; Giuseppe, Núm. 224].

I3r. Benarós, León, "Lugones: 23 años después", TPr., Año I, Núm. I, I5 de marzo de i96r, pág. I7.

132. Berenguer Carisomo, Arturo y Bogliano, Jorge, Medio sigla de literatura americana (Madrid: Instituto de Cultura Hispánica, 1952), págs. $74-84$.

I33. Berisso, Emilio, "Leopoldo Lugones", Rev. Nac. Lit., III, págs. I $40-I_{42}$.

r34. Berisso, Luis, "El artista", Nos. [cit. en Núm. I], págs. 7-8.

I35. Bernández, Francisco Luis, "Los romances criollos de Lugones" [sobre Romances del Río Seco], Sur, IX, Núm. 56, mayo de 1939, págs. 70-72.

—, "Lugones", Crit., Núm. I237, 9 de junio de 1955, págs. 407-408.

136. Betancourt, José, "El espíritu americano" [Comparación entre el americanismo de Rodó y el de Lugones], Rep. Amer., XII, 269 [Tomado de La vanguardia de Barcelona].

137. Bietti, Oscar, "Una antología de Lugones", Nos., Segunda época, Año IV, T. XV, Núm. 68, noviembre de I94I, págs. 222-224.

138. Blackwell, Alice Stone, Some Spanisb-American Poets. Translated by... With an Introduction and Notes by Isaac Goldberg (New York: D. Appleton and Co., 19r9), págs. 326-338 y 554.

I39. Blanco Fombona, Rufino, "Prólogo" a Julio Herrera y Reissig, Peregrinos de piedra (París: Casa Garnier, 1912). —-, "Leopoldo Lugones", Gac. Lit. M., I5 de febrero de 1929. _- El modernismo y los poetas modernistas (Madrid: Editorial Mundo Latino, 1929), págs. 295-337.

I 40. Bonet, Carmelo M., "Leopoldo Lugones", Nos. [cit. en Núm. I], págs. I32-I4I.

-, "Leopoldo Lugones", en Voces argentinas (Buenos Aires: Librería del Colegio, I940), págs. 41-65. 
—, "Palabras sobre La guerra gaucha", Nac., 28 de julio de I957.

r4T. Borges, Jorge Luis, "Sobre Romancero", Inic., II, Núm. 9, págs. 207-208 [Recogido en El tamaño de mi esperanza (Buenos Aires: Ed. Proa, I926), págs. I02-I03].

—, "Las nuevas generaciones literarias", Hog., 26 de febrero de 1937 [Recogido en Leopoldo Luganes (Buenos Aires: Ediciones Troquel, 1955], págs. 75-80).

—, "Leopoldo Lugones", Sur, VIII, Núm. 4I, febrero de 1938, págs. 57-58: Repr. Amer., I9 de marzo de I938.

-, "Lugones", Nos. [cit. en I], págs. I50-I52 [Recogido en Leopoldo Lugones (Op. cit)], págs. 8I-84.

- "Lugones, Herrera, Cartago", Cur. Conf., Año XXIV, Vol. 46, Núm. 268, marzo de I955, págs. I-4 [Recogido en Leopoldo Lugones, págs. 85-90].

- Leopoldo Lugones. Ensayo escrito con la colaboración de Betina Edelberg (Buenos Aires: Ediciones Troquel, I955). —., "A Leopoldo Lugones", en El bacedor (Buenos Aires: Emecé Editores, S. A., r96r) págs. 7-8.

I42. Botana, Natalio, "Señor don Leopoldo Lugones", Nac., I4 de julio de 1923.

I43. Bóveda, Xavier, "Un artículo crítico sobre la obra de Lugones" [Aparecido en La libertad, de Madrid, el 23 de noviembre de 1923], Nac., 24 de noviembre de 1923.

- "Leopoldo Lugones. Estética. El supuesto antiespañolista. El gran equívoco. Colofón", D. Esp., 24 de febrero de I924.

I44. Bravo, Mario, "Leopoldo Lugones en el movimiento socialista", Nos. [cit. en I] págs. 27-47.

I45. Brenes Mesén, Roberto, "El gobierno de los mejores. En defensa de Lugones", Rep. Amer., XI, 49-50 [Lugones contesta en "De Leopoldo Lugones a Roberto Brenes Mesén"], Rep. Amer., XI, págs. $245-247$.

—, "Leopoldo Lugones", Rev. Iber., Vol. I, Núm. I, mayo de I939, págs. IO-I 2.

—., "El ejército de la Iliada", en Crítica americana (San José, Costa Rica: Ediciones "El Convivio", I936), págs. 7-I2.

I46. Bunge, Augusto [Carta de Lugones sobre Bunge y respuesta de éste], en Polémicas. Prólogo de Roberto F. Giusti (Buenos Aires: Cooperativa Editorial Ltda., r9ז8), págs. r6I-172 y I73-182. 
I47. Bunge, Roberto J., "Libros del mes: El imperio jesuitico"; ideas, Núm. I7, septiembre de 1904, págs. 79-88; Coj. Ilust., XIII, págs. 74I-742.

x48. Bunge de Gálvez, Delfina, "Lugones y la barbarie cristiana", Hog., 23 de febrero de 1923 .

\section{C}

r49. Calandrelli, Matías, "Leopoldo Lugones", La Pr., abril de r9o5 [No he podido verificar la fecha exacta].

150. Caillet-Bois, Julio, Antología de la poesía bispanoamericana (Madrid: Aguilar, r958), págs. 897-9rI.

I5r. Cambours Ocampo, Arturo, Indagaciones sobre la literatura argentina (Buenos Aires: Editorial Albatros, 1952), págs. 37-44.

- Lugones. El escritor y su lenguaje (Buenos Aires: Ediciones Theoria, 1957), págs. 19-29.

152. Camp, Jean, La guirnalde espagnole. Les cent plus belles fleurs $d_{u}$ sonnet espagnol transplantées en teme francaise. Prologue d'Alphonse Reyes (México: Le Coq Français, I947).

153. Campos, Jorge, Antología bispano-amenicana (Madrid: Ediciones P'egaso, r950), págs. 366-367.

- "Leopoldo Lugones" en Diccionario de literatuna española (Madrid: Revista de Occidente, 2da. ed., I953), pág. 425.

154. Cansinos-Assens, Rafael, La nueva literatura. III. La evolución de la poesía (Madrid: Editorial Páez, I927), págs. 362-363.

155. Capdevila, Arturo, "La formación de Lugones", Nos. [cit. en I], págs. 322-330; Boletin de la Academia Nacional de la Historia, Buenos Aires, XII, r939.

- "Leopoldo Lugones y Córdoba", Vang., 3 de septiembre de I939.

- "Leopoldo Lugones", RNC., Núm. I4-I5 (I939-I940), págs. $89-96$.

- "Leopoldo Lugones el semidiós", RNC., Núm. I6 (1940), págs. II5-137; Núm. I7 ( I940), págs. I48-156; Núm. 26 (1941), págs. 84-94; Nủm. 29, págs. 96-102; Núm. 30, págs. $59-67$.

I.56. Carbonell y Rivero, José Manuel, Alretedor de un gran poeta: 
Leopoldo Lugones [Conferencia pronunciada el día I7 de marzo de I9I2 en el Conservatorio Nacional de Música] (La Habana, Cuba: Imprenta Seoane y Alvarez, I9I2), 3 I págs.

157. Carilla, Emilio, "Sobre la elaboración poética en Lugones", $H_{k i} T$., Año II, Núm. 5, I954, págs. I67-I84 [Hay sobretiro].

158. Carreño, Carlos H., Lugones (Córdoba: Editorial Centro, I950) [Contiene: "Boceto sobre Lugones", de Raúl J. Villafañe; un estudio del R. P. Jeremías Gutiérrez, un "Romance a la cautivita", de Gaspar Pío del Corro, y otros ecos del homenaje al poeta en la casa natal de la Villa María del Río Seco].

159. Carrizo, César, "Leopoldo Lugones" [En La Rioja], Nac., 25 de febrero de $\mathrm{x} 940$.

—, "Leopoldo Lugones en Mendoza. El poeta llega a la ciudad andina", Nac., r6 de noviembre de r94I.

_- "Leopoldo Lugones en Mendoza: la palabra del poeta", Nac., 21 de diciembre de r94r.

-, "Un amigo de Leopoldo Lugones. Recuerdo de Ojo de Agua", Nac., i9 de febrero de I94r.

I60. Carsuzán, María E., "El habla de los argentinos en la literatura. Primeros testimonios del lenguaje ciudadano", Nac, I2 de diciembre de $x 944$.

- La creación en la prosa de España e Hispanoamérica (Buenos Aires: Editorial Raigal, I955), II, "Creadores del siglo $\mathrm{xIx}$ y principios del $\mathrm{xx}$ ".

16r. Cassou, Jean [Véase Encyclopédié Française].

162. Castagnino, Raúl H., "¿Lugones escribió teatro?", BET., III, Núm. 9, I945, págs. 57-63.

163. Castellani, Leonardo, "Lugones, prosa y verso", Crit., Año VIII, Núm. 399, r935, págs. 188-r9o.

—., "Sentir la Argentina. Leopoldo Lugones", Nac., $x^{0}$ de mayo de r 938.

-, Sentir la Argentina. Leopoldo Lugones (Buenos Aires: Editorial Adsum, 1938) [Folleto de 38 págs., incluido en Critica literaria (Buenos Aires: Editorial Denca, 1945, págs. 2I8-446), con ampliaciones y cambios].

r64. Castor, R. M., "El cruel escepticismo de Lugones", El dia, San Salvador, ro de abril de r926; Rep. Amer., XII, 263. 
165. Castro Leal, Antonio, "Prólogo" a Poesias de Leopoldo Lugones (México, I917).

r66. Cejador y Frauca, Julio, Historia de la lengua y literatura castellana, comprendidos los autores iberoamericanos [14 Vols.] (Madrid: Tip. de la "Revista de Archivos, Bibliotecas y Museos", I915-1922), T. XI, págs. I 36-I42.

167. Cerretani, Arturo, "Leopoldo Lugones", Books Abroad, XII, I938, págs. 409-4II.

I68. Cócaro, Nicolás, "Leopoldo Lugones, cuentista", Nac., 27 de septiembre de 1953 .

- Cuentos fantásticos argentinos (Buenos Aires: Emecé Editores, 1960), págs. 58-69.

I69. Coester, Alf red, Literary History of Spanish America (New York: The Macmillan Co., I916), págs. 467-468 [Hay traducción española de Rómulo Tovar: Historia literaria de la América espictñola (Madrid: Hernando, I929)].

—, An Anthology of the Modernista Movement in Spanish America (Boston: Ginn and Co., 1924), págs. I42-147 y 292-293.

I70. Collier's Encyclopedia [Véase: Diccionarios. Núm. r92, y Marichal, Juan, A.].

1.71. Contreras, Francisco, Les écrivans contemporains de l'Amérique espagnole (París: La Renaissance du Livre, 1920), págs. 23-28. - L' esprit de l'Amérique espagnole (París: Collection de la Nouvelle Revue Critique, r93 I), págs. 45-53.

172. Coronado, Nicolás [Ver Núm. II8].

173. Corro, Gaspar Pío del, Algunos antecedentes de "La guerra gatrcba" de Leopoldo Lugones (Córdoba, Argentina: Universidad Nacional de Córdoba. Facultad de Filosofía y Humanidades. Instituto de Literatura Argentina e Iberoamericana, r959) [Folleto de 29 págs.; copias a máquina con tapas impresas].

—, [Véase también Núm. 158].

174. Cossío, Carlos, "La nueva generación y Leopoldo Lugones", Nos., Año XIX, T. 50, Núm. 192, mayo r925, págs. 98-105.

175. Cowes, Hugo Washington, "Leopoldo Lugones", Nos. [cit. en I], págs. I02-I05.

176. Craig, George Dundas, The Modernist Trend in Spanisb-Amer- 
ican Poetry (University of California Press, 1934), págs. 96-Ixr; 290-295 y 345 .

r77. Crispo Acosta, Osvaldo, Motivos de critica bispanodmericand (Montevideo: Imprenta y Librería Mercurio, de Luis y Manuel Pérez, I9I4), pág. I70 y ss.

178. Crow, John A. [Ver Núm. 266].

r79. Cúneo, Dardo, "Mariátegui y Lugones", Humanismo, México, III, Núm. 23, I954, págs. 47-55.

- El romanticismo político (Buenos Aires: Ediciones Transición, x955), págs. 35-47.

- "Internación en Lugones", Rev. Soc., Año VIII, Núm. 94, marzo de 1938, págs. 212-216.

\section{$\mathrm{CH}$}

180. Chamber's Encyclopedia [Ver Diccionarios, Núm. I92, y Entwistle, William James].

r8r. Chiáppori, Atilio, "La lección de Lugones", Nos. [cit. en I], págs. 53-57.

r82. Chumillas, Ventura, Letras argentinas (Buenos Aires: J. Vigil), I930.

- Crónicas y criticas literarias (Buenos Aires: Editado por "El Pueblo", órgano nacional del catolicismo argentino, I936) [Comentarios a un libro de Guillermo E. Laffite. Véase: Laffite, Guillermo E.].

D

I83. Dabini, Atilio, "Leopoldo Lugones", $O y O$., Nưm. r8, r940, págs. 42-45.

184. Daireaux, Max, Panorama de la littérature Hispano-Americane (París: Éditions Kra, [1930]), págs. I23-ז25.

I85. Darío Rubén, "Un poeta socialista: Leopoldo Lugones", El tiempo, Buenos Aires, 12 de mayo de 1896; Nos. [cit. en Núm. I], págs. I22-I3r.

-, "Leopoldo Lugones", en Las montañas del oro. . [Véase Núm. 2], págs. 7-10 [Véase también Núm. 55, págs. 3-6]. 
—, "Cabezas: Leopoldo Lugones", MM., Vol. II, Núm. I, noviembre de I9II, págs. 35-37; Cabezas... (Buenos Aires: Ediciones Mínimas, Nủm. 6, 1916), págs. 7-9; Cabezas: pensadores $y$ artistas politicos, en Obras completas (Madrid: Editorial Mundo Latino, I9I9), T. XXII, págs. 53-57; Los raros. Cabezas... (Madrid: Editorial Aguilar [Colección Crisol], 1945), págs. 355-359.

[Los apellidos que comienzan con la preposición de y su contracción del, como De Matteis, De Pedro, De Vitis, Del Corro y Del Saz, véase por Matteis, Pedro, Vitis, Corro y Saz].

186. Der Grosse Brockhaus [Véase en Diccionarios, Núm. I92].

187. D'Halmar, Augusto, "Tres amigos que se nos van", Atenea, LV, I939, págs. 78-84.

I88. Díaz Bialet, Agustín, "Leopoldo Lugones. Génesis y progreso de sus ideas", RUNC., Año XXVII, Núm. I-2, r940, págs. 46-77.

189. Díaz Pérez, Viriato, "Leopoldo Lugones", Rev. Inst. Parag., Año $\mathrm{X}$, Núm. I62, págs. $847^{-850}$.

I90. Diaz Plaja, Guillermo [Director], Historia general de las literaturas hispánicas [Véase Saz, Agustín del].

I9r. Díaz Villalba, E., "El rancho del gaucho de Caro (Recuerdos lugonianos)", Nac., i9 de febrero de I939.

r92. DICCIONARIOS Y ENCICLOPEDIAS:

An Encyclopedia of Latin-American History [Véase Martin, Michael Rheta... Núm. 3I2].

Collier's Encyclopedia (New York: The Crowell-Collier Publishing Co., I96I). Vol. I2, págs. I49-150 [Nota de Juan A. L. Marichal].

Chamber's Encyclopoedia (London: George Newres Limited, I959), pág. 24 [Nota de William James Entwistle].

Der Grosse Brockbaus (F. A. Brockhaus Wiesbaden, 1955), Vol.

7, pág. 374 .

Diccionario de la literatura universal [Ver Ruiz, Luis Alberto].

Diccionario de literatura española (Revista de Occidente, I949; 2da. ed., I953) [Ver Campos, Jorge, Núm. I53].

Diccionario Enciclopédico U.T.E.H.A. (México: Unión Tipográfica Editorial Hispano Americana, I953), pág. 1,229. 
Diccionario Histórico Argentino [Véase Piccirilli, etc., Núm. 380]. Diccionario Universal de Escritores [Véase Minchero, etc., Núm. 324].

Dictionary of Spanish Literature [Véase Newmark etc., Núm. 344].

Dizionario universale della letteratura contemporanea [Véase Mondadori, etc., Núm. 33I].

Enciclopedia Italiana [Véase Bartolini, etc., Núm. $\times 27$ ].

Enciclopedia Italiana Treccani (Roma, 1934). Vol. 2I, pág. 6I3. Enciclopedia Universal Ilustrada Europeo-Americana [Hijos de Espasa-Calpe] (Barcelona: Espasa-Calpe, editores, s. f.), Vol. 3I, pág. 58I.

Encyclopoedia Britannica (Chicago-London-Toronto-Geneva, I96I), Vol. I2, pág. 32C [John E. Englekirk].

Encyclopedie Française (París, 1935). Vol. r7, págs. 44-45 [Jean Cassou].

Encyclopedia of Literature [Véase Shipley, etc., Núm. 4r8]. Ensayo de un diccionario de la literatura [Véase Sáinz de Robles, etc., Núm. 407].

Gran Enciclopedia Argentina [Véase Santillán, etc., Núm. 412]. New Century Cyclopedia of Names [Véase Núm. 343].

Nouvelle Larousse Universel [Véase Núm. 348]. The Encyclopedia Americana [Véase Núm. 436]. Who's who in Latin America [Véase Martin, Percy Alvin. Núm. 3I3].

193. Dickmann, Enrique, "Vida y muerte de Leopoldo Lugones", Vang., 20 de marzo de I938 [Reproducido de Conducta, II].

194. Díez-Canedo, Enrique, "Las Odas seculares, de Leopoldo Lugones", España (Madrid), 2 de febrero de 1924.

- - "Lugones y la libertad en el verso", en Letras de América (México: El Colegio de México, I944), págs. 323-33r.

195. Diez-Echarri, Emiliano y Roca Franquesa, José María, Historia de la literatura española e bispanoamericana (Madrid: Aguilar, I960), págs. I2r5-1216.

196. Doll, Ramón, "Sobre La grande Argentina", Vid. Lit., septiembre de I930; incluido en Crítica (Buenos Aires: Talleres Gráficos J. L. Rosso, I930). 
197. D'Ors, Eugenio ["Xenius"], "Lugones", en $E l$ nuevo glosario (Madrid: Aguilar, I92r), T. I. pág. 206 [El Glosario completo es de r952].

198. Echagüe, Juan Pablo, "Letras nacionales. Sobre La guevra gaucha", Nac., 27 de noviembre de 1905.

—, "El helenismo de Lugones", Vid. Hoy, Año II, Núm. 23, I938.

—_, "El sentido de la obra de Lugones" [Discurso pronunciado en la Academia Nacional de la Historia, Buenos Aires, i8 de junio de 1939], Nac., r9 de junio de 1938; Nos. [cit. en Núm. I], págs. 33 T-336. En francés: "Le sens de l'oeuvre de Lugones", Revue Argentine, París, Año V, Nủm. 28, I938, págs. 3-Ir.

- "Leopoldo Lugones", en Seis figuras del Plata (Buenos Aires: Editorial Losada, 1938), págs. 5I-68; Escritores de la Argentina (Buenos Aires: Emecé Editores [1945]), págs. I36-I43.

I99. Edelberg, Betina [Ver Núm. I4I].

200. E. J. M., "Medio siglo de Lunario", Nac., 8 de febrero de 1959.

20I. El Charrúa de la Torre [Ver Torre, El Charrúa de la].

202. E. M. [¿Evar Méndez?], "Comentario sobre la designación de Lugones para la Corporación Intelectual de la Liga de las Naciones", Mar. F., Núm. 7, 25 de julio de I924.

-, "Un gran proyecto de Lugones: Formación de un nuevo estado de conciencia" [Acerca de la reforma de la enseñanza; trabajo firmado por Lugones, con introducción de E. M.], Mar. $F$., Núms. I4 y I5, 24 de enero de 1925.

203. Enciclopedia [Ver Diccionarios. Núm. 192].

204. Enciso, Agustín, "Leopoldo Lugones", Not., Año II, Núm. 55, 25 de julio de 19I6, págs. 1083-1085.

205. Encyclopoedia [Ver Diccionarios. Núm. 192].

206. Englekirk, John E., Edgar Allan Poe in Hispanic Literature (New York: Instituto de las Españas, 1934), págs. 278-304. 
—, Ver Encyclopoedia Britannica (Ed. de 196I). Vol. I2, pág. 32c.

207. Entwistle, William James, en Chamber's Encyclopedia [Ver. Núm. I92].

208. Erro, Carlos Alberto, "Leopoldo Lugones", Nac., I3 de marzo de I949.

209. Espasa-Calpe, Enciclopedia... [Ver Diccionarios. Núm. I92].

210. Espinoza, Enrique [Samuel Glusberg], "El humorismo poético de Leopoldo Lugones', Rep. Amer., 24 de septiembre de 1927.

—-, "Confesión del amigo que vuelve", Nos. [cit. en I], págs. 310-318; Rep. Amer., I2 de noviembre de 1938.

_-, "La hora de la espada", en Trinchera (Buenos Aires:

B.A.B.E.L., I932).

—, "La síntesis genuina de Lugones", Rev. Ind., 2da. época, Núm. 40, 1942.

_-, El espiritu criollo: Sarmiento, Hernández, Lugones (Santiago de Chile: Editorial Babel, I952), págs. 94-108.

2II. Estrella Gutiérrez, Fermín, "Lugones, su vida y su ensueño", Arg. L., 7, 14 y 18 de marzo de 1940.

- - y Suárez Calimano, Emilio, Historia de la literatura americana y argentina (Buenos Aires: Editorial Kapelusz y Cía., 2da. edición, s. a.), págs. 349-357.

2I2. Fariña Núñez, Eloy, "Lugones", Pal., 20 de noviembre de I929.

213. Fernández, Juan Rómulo, "Lugones, hombre de voluntad", Nos. [cit. en I], págs. 95-98.

2I4. Fernández García, Alejandro, "Arrendajos" [Sobre la popularidad de L. Lugones, S. Díaz Mirón y Vargas Vila], Coj. Ilust., $\mathrm{XV}$, págs. $436 \cdot 437$.

215. Fernández Moreno, Baldomero [en Babel, citado en Núm. Ir8].

216. Ferrari Nicolay, Mauricio y Vidal Ferreyra, Videla, "Ubicación y mensaje de La guerra gaucba", EALP., junio de 1948, págs. 268278 . 
217. Ferreira, João-Francisco, Capitulos de literatuta bispano-americana (Porto Alegre, Brasil: Edições da Facultade de Filosofia, 1959), págs: 3 r 7 -320.

2r8. Figueira, Gastón, "Gloria y tragedia de Lcopoldo Lugones", ND., XXII, Núm. 3, I94I, págs. I2-I5.

_- "Evocación de Leopoldo Lugones", Rev. Nac., Año XV, Vol. 53, Núm. I58, febrero de 1952, págs. 194-200.

2x9. Fingerit, Julio, Un enemigo de la civilización: Leopoldo Lugones (Buenos Aires: Editorial Tor [1926]) (Folleto de 79 págs. en donde refuta $L a$ organización de la paz).

220. Flores, Angel, Historia y antología del cuento y la novela en Hispanoamérica (New York: Las Americas Publishing Co., 1959), págs. 249 -257.

22x. Franceschi, Gustavo, El caso Lugones (Buenos Aires: Unión Popular Católica Argentina, I923).

222. Frank, Waldo, Tales from the Argentine [Edited with a Foreword by Waldo Frank. Translated from Spanish by Anita Brenner. Illustrations by Mordecai Gorelik] (New York: Farrer and Rinehardt Incorporated, I930), págs. 79-102.

223. Frugoni, Emilio, "Lugones, precursor en poesía", Nos, [cit, en $x$ ], págs: 245-249.

\section{G}

224. Gabriel, José, "El antropoide", Critica, Buenos Aires, 20 de julio de 1923 .

_.., "El hombre en fuga", Nos. [cit. en r], págs. 99-IOI.

225. Gallo, Ugo y Bellini, Giuseppe, Storia della letteratura ispanoamericana (Milano: Nuova Accademia Editrice, I958), págs. 220-226.

226. Gálvez, Manuel, "Aclaración", Nac., is de junio de r9o3 [Respuesta a "Una aclaración", de Leopoldo Lugones, aparecida en Nac., I3 de junio de r903. Con el título de "El final de un incidente", en Nac., 16 de junio de 1903 , se termina la cuestión]. - "Letras argentinas", Rev. Am., julio de I9I4, págs. 224230.

_- La vida multiple. Arte y literatura (1910-1916) (Buenos Aires: Edición "Nosotros", x916), págs." 2×3-216 [Sobre El libro fiel]. 
-.,. "Un crítico argentino", Not., III, Núm. 142, 27 de mayo de I9I8, págs. 2993-2995.

—_L Los mejores cuentos [Selección y prólogo de Manuel Gálvez] (Buenos Aires: Editorial "Patria", I9r9), págs. I39I6r.

- "Desencuentros con Lugonè", iAqui está!, Buenos Aires, Núm. 533, 26 de junio de I94I, pág. 22 [Incluido en $R e$ cuerdos de la vida literaria. Amigos y maestros de mi juventud (1910-1916)] (Buenos Aires: Editorial Kraft, r944), págs. $219-237$.

227. Gandolfi Herrero, Arístides [Ver Yunque, Alvaro].

228. Gannon, Patricio y Manning, Hugo, Argentine Antbology of Modern Verse (Buenos Aires: Francisco A. Colombo, I942), págs. I4-r 8 y 24-27.

229. García, Germán, La novela argentina. Un itineratio (Buenos Aires: Editorial Sudamericana, I952), págs. I03; 175-176; 218-219, y 244 .

230. García Calderón, Ventura, "Le génie intellectuel sud-américain. Leopoldo Lugones. Le poète et son esthétique. L'humaniste", Fr. Amer, marzo de I92I, págs. ro2-I Io [Comentado en Nac., 5 de junio de I921].

—, "Leopoldo Lugones", Nos., Año XVI, T. 42, Núm. i6r, octubre de 1922, págs. 173-175; Rep. Amer., V, 1922, págs. I55-I56 [Se incluye como prólogo a El libro fiel, 2da. edición (París: Editorial Franco-Ibero-Americana, s. f. [1922]), págs. 9-15 [Ver Núm. 17].

_- "La literatura contemporánea en Argentina", Nos, Año XVI, T. 42, Núm. I63, diciembre de r922, págs. 564-565 [Reproducido de Comoedia, París, 2 de noviembre de 1922 ; tambièn se publicó en La Razón, Buenos Aires, 3 de diciembre de 1922].

--, En Babel [Véase Núm. Ir8].

de I938; Fr. Amer., Vol. XII, julio de I938 [Publicado como separata, incluyendo a los anteriores, con el título de "Leopoldo Lugones". (Genève: Imprimérie du Journal de Genève, r947], 68 págs. 
231. García Fernández, Manuel, "Leopoldo Lugones", OyO., Núm. 25, mayo de I942 págs. 58-6r.

—_ "Biografía de Lugones escrita por el hijo", El universal, Caracas, Venezuela, 8 de noviembre de 1955.

232. Gatcía Medina, Vicente, Disparates no usuales, pero usados por escritores de postin [Lugones, Monner Sans, R. Rojas] (Buenos Aires, I924 [Hay una segunda serie de I929].

233. García Monge, Joaquín, "Cartas de Lugones", Rep. Amer., ig de marzo de 1938 (Reproducido con el título de "Cuatro cartas de Lugones", Nos. cit en $\mathrm{x}$, págs. 352-356].

—, "En Lugones pensamos", Rep. Amer., 17 de junio de I939.

234. García Prada, Carlos, Poetas modernistas bispanodmericanos (Madrid: Ediciones Cultura Hispánica, I956), págs. 267-283 y 345. - Poesía de España y América (Madrid: Ediciones Cultura Hispánica, 1958), T. II. págs. 665-670.

235. Gatica Martínez, Tomás, Ensayos sobre literatura bispano-americana (Santiago de Chile: Editorial Andes, 1930), págs. I9I-r94.

236. Gellini, Antonio, "Leopoldo Lugones, periodista", Nos. [cit. en I], págs. 308-309.

237. Gerchunoff, Alberto, "La política de Leopoldo Lugones", Not., III, Núm. I05, II de agosto de I9I7, págs. 2098-2100 [Véase Núm. II8].

-.., "Leopoldo Lugones", PU., Núm. 42, octubre de I9I9.

_- "Leopoldo Lugones" [artículo necrológico], Nac., 20 de febreto de 1938 .

_- "Poeta de la patria fue Lugones: Reposó en la canción de la tierra y evocó en la lengua de los viejos gauchos la Argentina primitiva" [Discurso en representación de la Sociedad Argentina de Escritores en el homenaje tributado en Villa María del Río Seco, en la casa en que nació Leopoldo Lugones], Idea, Año I, Núm. 9, I939, pảg. 5; Rep. Amter., ro de febrero de I940; 2 do. Congreso de la Sociedda Argentina de Escritores (Buenos Aires, I940), págs. 57-63.

238. Ghiano, Juan Carlos, "Quevedo y su presencia en las letras aregntinas", Logos, Facultad de Filosofía y Letras, Universidad 
de Buenos Aires, Año V, Núm. 8, I946, págs. II9-I26 [Sobre Lugones, págs. I2I-r23].

-, "Algunos temas lugonianos", Cur. Conf. Año XV, Vol. 30, marzo de 1947 , págs. 347-359.

- - "Lugones escritor: sus problemas (a propósito de La guerra gaucba)", BAAL., XVI, Núm. 62, noviembre-diciembre de I947), págs. 735-764.

- - "Lugones y el lenguaje", RUBA., 4ta. época, Año II, Núm. 5, enero-marzo de I948, págs. 49-75 [hay sobretiro].

_-, "Aptitud de Lugones", en Temas y apititudes (Buenos Aires: Editorial Ollantay, I949), págs. 9-I7.

-_., "Actitud de Lugones", Realidad, Buenos Aires, Año III, Vol. 5, Núm. I5, mayo-junio de I949, págs. 342-348.

—, "Situación de Lugones", Reunión, Buenos Aires, Núm. 8, marzo-abril de I952, págs. 33-34.

- Lugones escritor. Notas para un analisis estilistico (Buenos Aires: Editorial Raigal, I955).

- Poesia argentina del siglo XX (México-Buenos Aires: Fondo de Cultura Económica [Colección Tierra Firme, 65], I957), págs. 29-40.

239. Ghida, Arturo Hotacio, "Los cuentos criollos de Lugones", Cultura, La Plata, Argentina, Núm. 5, 1950, págs. 73-86.

240. Ghío, Haydée M., "Una visita al museo lugoniano", Hog., 8 de abril de $x 949$.

24I. Giménez Pastor, Arturo, "Líneas sobre Lugones", Nos. [cit. en I], págs. 64-68.

-, Historia de la literatura argentina (Buenos Aires-Montevideo: Editorial Labor, S. A., I945), T. II, págs. 465-471.

242. Giménez Rueda, Julio [Véase Jiménez Rueda, Julio].

243. Giner de los Ríos, Gloria, El paisaje de Hispanoamérica a través de su literatura [Antología] (México: Imprenta Universitaria, I958), págs. I I6 y 227-228.

244. Giorgi, Manuel V., Curso de bistoria de la literatura bispanoamericana (Buenos Aires: Talleres Gráficos "El Misionero", I937), pág. 360 .

245. Girosi, Pablo, "Resonancias itálicas en la poesía de Leopoldo Lutgones", Hist., Núm. 6, marzo de I948, pág. I87-I94. 
246. Giusti, Roberto F., "Leopoldo Lugones: "El imperio jesuitico", Nos., Año II, Núms. to y II, mayo-junio de I908, págs. 327-332.

—, "Leopoldo Lugones" [A propósito de Lunario sentimental], Nos., Año III, T. 4, Núms. 22 y 23, julio-agosto de I909, págs. 290-306 [Incluido en Nuestros poetas jóvenes. Revista critica del actual movimiento poético argentino (Buenos Aires: Ediciones "Nosotros". Albasio y Cía., I9II), págs. I57-I90.

-.., "Leopoldo Lugones", en Nuestros poetas jóvenes, [ed. cit.], págs. 34-5 I [Sobre Las moniañas del oro, Los crepúsculos del jardín, Lunario sentimental y Odas seculares]; en págs. 182-190, "Leopoldo Lugones y su obra" [sobre la obra del mismo título de Juan Más y Pí; carta abierta publicada en Nos., Año IV, T. 5, Nủm. 27, abril de I9rI, págs. 226$23 \mathrm{I}$.

, Historia de Sarmiento, por Leopoldo Lugones", Nos., Año IV, T. 5, Núm. 28, mayo de I9II, págs. 299-30I.

—-, "Lugones helenista", Nos., Año X, T. 22, Núm. 84, mayo de I9I6, págs. I80-I83.

—-, "Lugones, fiel a sí mismo", Crítica, Buenos Aires. 19 de julio de 1923 .

—, En Babel [Véase Núm. II8].

—- En Literatura y vida (Buenos Aires: Edición de "Nosotros", 1939), págs. 68-73.

—, En Prampolini, Historia aniversal de la literatura (Buenos Aires: UTHEA Argentina, I94I), T. XII, págs. 52I-522 [Hay segunda edición de México].

_- En Lecciones de literatura argentina e bispano-americana $y$ antología anotadd y comentada (Buenos Aires: Editorial Estrada, I957), págs. $475-487$.

_- "Las letras argentinas en el siglo actual y sus antecedentes en el siglo XIX", en Joaquím de Montezuma de Carvalho [Director], Panorama das literaturas das Americas (Angola, I959), T. III, págs. 842-843.

—, En Arrieta, Rafael Albetto [Director], Historia de la literatura argentina (Buenos Aires: Ediciones Peuser, 1959), T. IV, págs. 460-462 [sobre el ensayista].

247. Glusberg, Samuel [Véase Espinoza, Enrique, y Babel, Núm. II8]. 248. Gómez Carrillo, Enrique, "Actualidądes literarias" [Sobre artícu- 
los políticos de Lugones en La montaña], Coj. Ilust., VII, pág. 436.

—-, "Poetas de América" [Sobre Las montañas del oro], Coj. Ilust., VII, págs. 228-230.

_- El encanto de Buenos Aires [Sobre "El tango"] (Madrid: Perlado, Páez y Cía., 19:4), págs. 213-223.

249. Gómez Haedo, Juan C., "Leopoldo Lugones", Rev. Nac., febrero de 1938 , págs. 316 ss.

250. González, Joaquín V., "El poeta y los pájaros. El libro de los paisajes, de Leopoldo Lugones", en Ritmo y linea (Buenos Aires: Talleres Gráficos de L. J. Rosso, I933, págs. 73-93; Idem., en Obras completas (Universidad Nacional de La Plata, Argentina, r936), T. 20, págs. 65-8I.

25r. González Arrilli, Bernardo, "Leopoldo Lugones", Esp. Hab., Vol. XI, Núm. 63, septiembre de 1938, págs. I30-I32.

252. Gonzảlez Carvalho, José, Indice de la poesia argentina contemporánea (Santiago de Chile: Ediciones Ercilla, I937) [Empieza con Lugones].

253. González Lanuza, Eduardo, "Lugones, la metáfora y mi generación" [a propósito de "Las nuevas generaciones literarias", de J. L. Borges], Hog., I2 de marzo de 1937.

254. Gorbea, Guillermo Julio, "La rima en el verso de Lugones", Nos., Segunda Epoca, Año II, T. 3, Núm. 13, abril de 1937, págs. 405-407.

255. Groussac, Paul, "Leopoldo Lugones", Bibl., Año II, 'T. 8, I898, págs. 265-266.

-, "Una carta de Paul Groussac" [Responde a un artículo de Lugones publicado en Nac., el II de mayo de I924], Nac., I5 de mayo de 1924 .

256. Guglielmini, Homero M., "Leopoldo Lugones", Clarin, Buenos Aires, 21 de noviembre de 1948.

257. Gutiérręz, Jeremías [Ver Carręño, Carlọs H., Núm. I58]. 
$\mathrm{H}$

258. Hamilton, Carlos, Historia de la literatura bispanoamericana. Segunda Parte, Siglo XX (New York: Las Américas Publishing Co., I96r), págs. 38-39.

259. Hardy, B. R., A Study of the Varied Talent of L. Lugones (M. A. Thesis, University of Kansas, 1934).

260. Havaux, León, En torno a unas conferencias del señor Leopoldo Lugones (Buenos Aires, r923) [Folleto de 46 págs.].

26r. Henríquez Ureña, Max, Breve bistoria del modernismo (México: Fondo de Cultura Económica, 1954), págs. I87-199.

262. Henríquez Ureña, Pedro, Horas de estudio (París: Librería L. Ollendorf, s. f. [I9ro], pág. i 6 , nota I [Lo llama "el Góngora americano"].

- Las corrientes literarias en la América Hispánica (México: Fondo de Cultura Económica, r949), págs. 193-r96.

—. Obra crítica. Edición, bibliografía e índice onomástico de Emma Susana Speratti Piñero. Prólogo de Jorge Luis Borges (México: Fondo de Cultura Económica, I960), págs. I82 y $305-307$.

263. Hernández Arregui, J. J., Imperialismo y cultura (Buenos Aires, 1957).

264. Herrera, L. P., Poesias. Antología hispanodmericana (Buenos Aires: L. J. Rosso, r932).

265. Herrero Almada, Benigno, "Anverso y reverso de un reportaje a Leopoldo Lugones", Hog., 2I de enero de 'I949.

266. Hespelt, E. Herman [Chairman and Editor], An Antbology of Spanish American Literature (New York: Appleton-CenturyCrofts, Inc., 1946), Vol. II, págs. 515-520.

- An Outline History of Spanish American Literature (New Yotk: S. F. Crofts and Co., I94r), págs. IoI-102 [La nota sobre Lugones pertenece a John A. Crow].

267. Hidalgo, Alberto, Muertos, heridos y contusos (Buenos Aires: Imprenta Mercatali, s. f.), págs. 32-38.

268. Holmes, Henry Alfred, Spanish America in Song and Story (New York: Holt Co., I932), págs. 44-46. 
269. Homenajes a Leopoldo Lugones.

Babel [Número dedicado a Lugones. Véase Núm. I 8 ].

"Homenaje a Leopoldo Lugones" [Palabras de Ventura García Calderón], en Fr. Amer., Núm. 3I9, I938, págs. 205-217.

"Homenaje a Leopoldo Lugones", BANH., XII, I939, págs. I49I 67 [Contiene: "La formación de Lugones", por Arturo Capdevila, y "Leopoldo Lugones", por Juan Pablo Echagüe; véase Núms. I55 y I98].

Nac., I9 de febreto de r939 [Artículos de Martínez Estrada, Pedro Miguel Obligado, Antonio Pérez-Valiente de Moctezumaj.

Nos. [Citado en Núm. I].

Saeta (Buenos Aires, T. II, Núm. I8-I9, I939, págs. 21-24 [Ho. menaje a Leopoldo Lugones de la Sociedad Argentina de Escritores].

\section{I}

270. Iglesias, Eugenio Julio, "Lugones hombre, muerto", Nos. [cit. en I], págs. 2I6-2I7.

27I. Insúa, Alberto, "El helenismo de Lugones", Vid. Hoy., I938, II, Núm. 23. "Carta abierta a Miomandre" [sobre la muerte de Lugones], Nos., Segunda Epoca, Año III, T. 8, Núm. 29, agosto de r938, págs. 28-30.

—, "Esta muerte indescifrable", Nos. [cit. en I], págs. I95r96.

\section{$\mathrm{J}$}

272. Jascalevich, Enrique Adolfo, "El amigo de Leopoldo Lugones" [Francisco Madrid], Hog., I2 de diciembre de I947.

273. Jiménez Rueda, Julio, "Una entrevista con Leopoldo Lugones", Rep. Amer., II, págs. 278-279 [Tomado de Revista de Revistas, México].

-, "Leopoldo Lugones, el último renacentista americano", Not., 6 de mayo de r92I.

- Bajo la Cruz del Sur. Impresiones de Sudamérica (México: Librería editorial de M. Mañón, I922) [Recoge la entrevista 
antes citada: sobre las ideas de Lugones en materia estética y solidaridad interamericana].

274. Jitrik, Noé, Leopoldo Lugones. Mito nacional (Buenos Aires: Ediciones Palestra, I960).

275. Johnson, Mildred E. [Translations by], Swan, Cygnets, and Owl. An Anthology of Modernist Poetry in Spanish America (Columbia, Missouri: The University of Missouri Studies, 1956), págs. 23, 79-80 y 103-107.

276. Jordán, Juan Manuel, "Leopoldo Lugones, visitador e inspector general de enseñanza secundaria y normal", Nos. [cit. en .I], págs. 283-298.

277. Justo, Luis, "A propósito de Lugones: La vieja y la nueva generación", Nos., Segunda Epoca, Año III, T. 8, Núm. 29, agosto de I938, págs. 76-79.

\section{K}

278. Kinnard, V., The Life, Works, and Significance of Leopoldo Lugones (M. A. Thesis: University of Washington, I934).

L

279. Lafitte, Guillermo E., A Leopoldo Lugones. Estampas de uno que viene para uno que se va (Buenos Aires: Porter Hnos., 1938) [Véase Núm. 182].

280. Lamarque, Nydia, "Negación de Leopoldo Lugones", Nos. [cit. en I], págs. $77-85$.

281. La Maza, Sara de, "El esteta", Nos. [citado en I], págs. III-II6.

282. Lamothe, Louis, Los mayores poetas latinoamericanos de 1850 a 1950 (México: Libro Mex Editores, I959), págs. x27-133.

283. Larreta, Enrique, "En la muerte de Lugones", Hog., 29 de abril de I938.

284. Lattanzi, L., "Recordando a Leopoldo Lugones: Más verdades sobre el Siglo de Hierro", Crit., XXXVII, r939, págs. 62-64. 
285. La Unión [Artículo anónimo en dicho periódico], "Un gran germanófilo", 6 de septiembre de I92I.

286. La vanguardia [Artículo anónimo], "Un Koloso [sic] del pensamiento", 8 de septiembre de I92I.

287. Laurel. Antología de la poesia moderna en lengua española [Selección a cargo de Emilio Prados, Xavier Villaurrutia, Juan GilAlbert y Octavio Paz] (México: Editorial Séneca [Laberinto], I94I), págs. 21-22, I4I-I95 y I227.

288. "Lauxar" [Ver Crispo Acosta, Osvaldo].

289. Lee, Muna, "Some Contemporary Latin American Poetry in English Version", $B P A U$., July, 1925.

290. Leguizamón, Julio, Historia de la literatura bispanoamericana (Buenos Aires: Editoriales Reunidas, I945), T. II, págs. 322-33I.

29r. Leguizamón, Martiniano, "Nuestros orígenes literarios", Nos., Año IV, T. 5, Núm. 29, junio de I9II, págs. 321-329 [En desacuerdo con la obra de Juan Más y Pí sobre Lugones. Se recoge en Páginas argentinas. Crítica literaria e bistórica (Buenos Aires: Librería Nacional J. Lajouane y Cía., editores, I9II), págs. 245263].

292. Lellis, Mario Jorge de, "Necesidad de una poética nacional", La Pr., 2I de noviembre de 1954 .

293. Lenzi, Carlos César, "Lugones", Not., 8 de julio de r92r.

294. Leviller, Roberto, "Lugones, vigia y sembrador", Nac., I7 de abril de 1938; Nos. [cit. en I], págs. 35I-364 [En francés: "Lugones, vigie et semeur", Rev. Arg., 1938, V, Núm. 26, págs. 28-35].

—, "Herrera y Reissig y Lugones", Rev. Nac., Núm. 9, septiembre de 1938, pág. 342 y ss.; Homage à Ernest Martimenche (París: Edition D’Artrey, I939), págs. 262-270.

295. L[izaso], F[élix], "Leopoldo Lugones" [Con motivo de su muerte], Rev. Cu., XI, febrero-matzo de I938, págs. 265-266.

296. Loncán, Enrique, "Significación y muerte de Leopoldo Lugones", Nos., Segunda Epoca, Año IV, T. 9, Núm. 36, marzo de I939, págs. 283-294. 
- Sens et mort de Leopoldo Lugones [Conferencia pronunciada en La Sorbone] (Paris: Société Industrielle D'Imprimerie, 1939), 23 págs.

297. López, Luis Carlos, "Leopoldo Lugones, Rev. Mod., II, pág. I80 [Firmado en Guanajuato, México, en I899].

298. López Merino, Francisco, "Leopoldo Lugones habla del ambiente literario argentino. Los autores no estudian", Rep. Amer., V, págs. I03-105 [Tomado de Nueva era, Buenos Aires].

299. López Palmero, Mariano, "Leopoldo Lugones. Trayectoria de una conciencia", Nos. [cit. en I], págs. 7I-76.

300. López Velarde, Ramón, "La derrota de la palabra", Vida moderna. (México) Año I, Núm. 30, I2 de abril de 1916 [Conferencia del 26 de marzo de 1916$]$. Recogida $E l$ don de febrero y otras prosas. Prólogo y recopilación de Elena Molina Ortega (México: Imprenta Universitaria, I952), págs. 232-239.

--, "La corona y cetro de Lugones", Vida Moderna (México), Año II, Núm. 55, I9 de octubre de r9I6. [Recogida en $E l$ don de febrero y otras prosas, págs. 268-273. Véase también págs. 69, 94, 252 (lo llama "el máximo Lugones") y 300 (lo llama "el sumo poeta")].

30r. Loprete, Carlos Alberto, "La literatura modernista en la Argentina (Buenos Aires: Editorial Poseidón, I955), págs. I08-124.

-, "Leopoldo Lugones, Fic., Núm. 2, julio-agosto de 1956, págs. $172-174$ y $176-178$ [Sobre los libros de Borges y Ghiano].

302. Lottero, Rómulo Nano, "El cansancio de Leopoldo Lugones", Nos. [cit. en I], págs. 213-215.

303. Lucero, Amador L., "Leopoldo Lugones", Tr., 3 r de junio de I905 [Véase también Babel. Núm. II8].

304. Lugones (h), Leopoldo, Mi padre. Biografia de Leopoldo Lugones con una composición inédita de Rubén Dario (Buenos Aires: Ediciones Centurión [Colección Ulises, 14], x949).

\section{$\mathrm{M}$}

305. Magis, C. H., La poesía de Leopoldo Lugones (México: Ediciones Ateneo, S. A., 1960). 
306. Mallea, Eduardo, "Adiós a Lugones", Rev. Ind., Segunda Epoca, Núm. 35, noviembre de 194I, págs. 364-382; Adiós a Lugones (Buenos Aires: Edición Colección Problemas Americanos. Talleres Gráficos "Augusta", 1942), 40 págs.; El sayal y la puirpura (Buenos Aires: Editorial Losada, I94I), págs. IIO-I26; 2 da. ed., I947, págs. I3I-150).

307. Mandolini, Hernani, "Leopoldo Lugones. Perfil sintético". Nos. [cit. en I], págs. I53-r56.

308. Manning, Hugo [Ver Núm. 228].

309. Merechal, Leopoldo, "Retrueque a Leopoldo Lugones", Mar. F., II, Núm. 26, 29 de diciembre de I925.

-, "Filípica a Lugones y otras especies de anteayer", Mar. F., II, Núm. 32, 4 de agosto de $x 926$.

- y Elbia R. de Marechal, Antología didáctica de la prosa Argentina (Buenos Aires: Editorial Kapelusz, 1954), págs. 621-629.

310. Marichal, Juan A. L. [Ver Collier's Encyclopedia, Núm. I92].

3II. Márquez, Narciso, "En torno a Lugones", Rev. Soc., Año IX, Núm. 99, agosto de 1938, págs. I22-I27.

312. Martín, Michael Rheta and Lovett, Gabriel H., An Encyclopedia of Latin American History (New York: Abelard-Schuman Limited, 1956), pág. 222.

3r3. Martin, Percy Alvin, Who's who in Latin America (Stanford University Press: Irst. edition), pág. 224.

314. Martínez Estrada, Ezequiel, "Poemats solariegos, de Leopoldo Lugones", Vid. Lit., abril de r929; Babel (Santiago de Chile), 4to. trimestre de I95r, págs. I9I-I92.

_-, "In memoriam", Nac., I9 de febrero de I939.

—, "Hudson y Lugones", Mov., Año I, Núm. 2, agosto de I94I, pág. I.

- Panorama de las literaturas (Buenos Aires: Editorial Claridad, 1946), págs. 322-325.

—-, "Efigic de Leopoldo Lugones. Prolegómenos pata una crítica", $L a$ Pr., I6 de septiembre de I956.

—_, "Quiroga y Lugones", en Cuadrante del pampero (Buenos Aires: Editorial Deucalión, 1956), págs. I83-190.

- "Lugones escritor, de Juan Carlos Ghiano", Com., Año III, Núm. 12, julio-septiembre de I956, págs. 95-96. 
Novedades (México), in de enero de I959 [Ver también Melián Lafinur, Alvaro, Núm. 32r].

315. Martínez Zuviría, Gustavo, El gran cuento del tío en la literatura nacional (Santa Fe, Argentina: 2da. edición, 1907).

316. Más y Pí, Juan, Leopoldo Lugones y su obra (Estudio crítico) (Buenos Aires: Edición Renacimiento, Igrr) [Reseña R. F. Giusti en Nos, Año IV, T. 5, Núm. 27, abril de I911, págs. I80-I83; contesta Más y Pí con "Sobre unas críticas", Nos., Año IV, T. 5, Núm. 30, julio de I9rI, págs. 23-27.

317. Matteis, Emilio de, Panorama della letteratura argentina contemporanea (Genova: Casa Editrice Nazionale, I929), págs. 2I-22.

3r8. Mazzei, Angel, Lecciones de literatura americana y argentina. Con antología comentada y anotada (Buenos Aires: Editorial Ciordia, S.R.L., I958), págs. 327-33I.

3r9. McMahon, Dorothy, "Leopoldo Lugones, a man in search of roots", MPh., T. LI, Núm. 3, 1954, págs. 196-203.

320. Mejía Nieto, Arturo, "Lugones, hombre de América", Nos. [cit. en I], págs. ro6-iтo.

32I. Melián Lafinur, Alvaro, "Leopoldo Lugones: Poemas solariegos", Rep. Amer., XVIII, pág. 345 [Tomado de Nac.].

—., "El libro fiel, por Leopoldo Lugones", Nos., Año VII, T. Io, Núm. 47, I9I3, págs. 79-83; Literatura Contemporánea (Buenos Aires: Sociedad Cooperativa Editorial Limitada, I918), págs. 82-87.

- y Martínez Estrada, Ezequiel, Homenaje a Leopoldo Lugones (Discursos) (Buenos Aires: Comisión Honoraria de Bibliotecas Públicas Municipales, r943), 24 págs.

322. Méndez Calzada, E., "Leopoldo Lugones", Rev. Arg., IV, Núm. 25, 1938, págs. 28-3I; Pro y contra (Buenos Aires: Jesús Menéndez, I930).

323. Meza Fuentes, Roberto, "Significación de Leopoldo Lugones", Mer., 7 de marzo de 1937 .

324. Minchero Vilasaró, Angel, Diccionario aniversal de escritores (San Sebastián, España: Edidhe, r957), T. II, págs. ro6-ro7. 
325. Miomandre, Francis de [Sobre El libro fiel, a propósito de la edición de París], Nac., 9 de abril de I923.

-. "El destino de los poetas es el de morir de hambre" [Sobre la muerte de Lugones], NL., 9 de abril de r938; Nos. [cit. en I], con el título de "Una información equivocada", con rectificación de Roberto F. Giusti.

326. Miri, Héctor F., "Al pie del Cerro del Romero", Steta (Buenos Aires), Il, Núm. I8-19, 1939, págs. 17-20.

327. Mistral, Gabriela, Letras para mujeres (México: Secretaría de Educación, 1923) [Ver también Núm. ri8].

328. Mitre, Adolfo, "El poeta de la patria", Nac, 9 de julio de r939.

329. Molina, Enrique, "Teoría y práctica del hispanoamericanismo", Mar. F., Núm. 17, I7 de mayo de 1925.

-., "La ideología del señor Lugones", Atenea, Año 2, Núm. 3[3(13)], mayo de 1925, págs. 287-300; Rep. Amer., X, 297-300; Por los valores espirituales (Santiago de Chile, 1925; 2da. edición: Santiago de Chile: Nascimiento, r942).

330. Molina Téllez, Félix, "Al pie del Cerro de la Cruz", Nos., Segunda Epoca, Año IV, T. II, Núms. 44 y 45 , noviembre y diciembre de 1939, págs. 223-226 [Sobre la visita del 2do. Congreso de Escritores de Córdoba a la casa donde nació Lugones en la Villa de Río Seco].

331. Mondadori, Alberto [Direttore], Dizionario universale della letteratura comtemporanea (Arnoldo Mondatori Editore, 196r), págs. 238-239.

332. Monges, Carlos H., La poesia de Leopoldo Lugones (México: Ateneo, I960).

333. Monteavaro, Antonio, "Leopoldo Lugones", Mer. Am., junio-julio de 1899.

334. Montenegro, Adelmo R., "Lugones y el modernismo hispanoamericano", RHC., 2do. Año. Núm. 2, Vol. r, abril de I959, págs. 3-20.

335. Monterde, Francisco, Antologia de poetas y prosistas bispanoamericanos modernos (México: Publicaciones de la Universidad Nacional, r931), págs. 88-95. 
336. Montero, Belisario J., De mi diario (Bruselas: P. Weissembuch, Impr. del Rey, s. f.), págs. 203-223 [Sobre Las montañas del oro].

337. Morales, Enesto, Antologia argentina. Poetas modernos (Buenos Aires: El Ateneo, 1924).

- Antología de poetas americanos (Buenos Aires: Santiago Rueda, editor, r94I), págs. 475-486.

_- Literatura argentina (Buenos Aires: Editorial Atlántida [Colección de Oro de Cultura General], I944), págs. I28-r3I. - y Novillo Quiroga, D., Antología contemporánea de poetas argentinos (Buenos Aires: Establecimiento de Artes Gráficas de A. Ferriol, 1917).

338. Moreno, J. C., "Las últimas ideas de Lugones", Crit., XXXVI 1938, págs. 428-430.

\section{$\mathrm{N}$}

339. Nalé Roxlo, Conrado, "Leopoldo Lugones el poeta", Clarin (Buenos Aires), I2 de octubre de 1947, págs. 6-7.

340. Navarro Monzó, Julio, "La búsqueda trágica", Nos. [cit. en I], págs. 204-208.

34I. Nelson, Ernesto, "Leopoldo Lugones, educador", Nos. [cit. en I], págs. 270-282.

342. Nervo, Amado, "Leopoldo Lugones" [Análisis de Las montañas del oro y Los creprisculos del jardin], Rev. Mod., XIII, págs. 276-285.

343. New Century Cyclopedia of Names (New York: Appleton-Century-Crofts, Inc., 1954), Vol. 2, pág. 2537.

344. Newmark, Maxim, Dictionary of Spanish Literature (New York: Philosophical Library, I956), págs. 201-202.

345. Neyra, Joaquín, "Leopoldo Lugones, por Jorge Luis Borges", Vea $y$ lea (Buenos Aires), 8 de marzo de $x 956$.

346. Noé, Julio, "Leopoldo Lugones: El payador", Nos,, Año X, T. 24, Núm. 90, octubre de r9r6, págs. 92-95.

- "La poesía argentina moderna", Nos., Año XXI, T. 57, Núm. Extraordinario, agosto de 1927, págs. 69-74. 
-, Antología de la poesia argentina moderna (I900-1925) (Buenos Aires: Edición "Nosotros", 1926; 2da. edición: Antología de la poesía argentina moderna (I896-1930). Buenos Aires: El Ateneo, I93I, págs. I3-83).

- En Arrieta, Historia de la literatura argentina (Buenos Aires: Ediciones Peuser, r959), T. IV. págs. 66-68.

347. Nosotros. A Leopoldo Lugones. Número Extraotdinario [cit. en I].

348. Nouvelle Larousse Universel (París: Librairie Larousse, 1949), T. II, pág. 95 .

349. Novillo Quiroga, D. [Véase Núm. 337].

350. Novión de los Ríos, "Una generación de poetas argentinos", Sur, Núm. 84, septiembre de 194r, págs. 57-62 [Sobre Lugones, pág. $58]$.

35r. Novo, Salvador [Editor], Antologia de cuentos mexicanos e bispanodmericanos (México: Editorial Cultura [Biblioteca Universo, T. I, Núm. 2], 1923).

352. Núcleo Diógenes, Ideario nuclear (Buenos Aires: El Ateneo, 1928), págs. $263-265$.

353. Núñez, Jorge A., Leopoldo Lugones (Córdoba, Argentina: Imprenta de la Universidad, 1938) [Conferencia pronunciada el Io de agosto de I938, en el Colegio Nacional de Monserrat]; 28 págs.

- Leopoldo Lugones (Córdoba, Argentina: Universidad Nacional de Córdoba. Facultad de Filosofía y Humanidades, I957).

354. Núñez Rentería, Dante, "Sí, Lugones", Hist., Núm. I44, mayo de r95I.

355. Obligado, Carlos, La cueva del fósil. Diálogos increíbles sobre la vida literaria argentina. Primera Serie (Buenos Aires: Librería y Editorial "La Facultad", I927).

—_, La cueva del fósil. Diálogos increibles sobre la" mida litera- 
ria argentina. I. De la poesia de Leopoldo Lugones (Buenos Aires: "La Facultad", I938).

—-, Prólogo a la Antología poética de L. L. [Ver Núm. 57].

356. Obligado, Jorge, "Influencia del gaucho y su literatura en el argentino contemporáneo", Memoria del Segundo Congreso Internacional de Cafedráticos de Literatura Iberoamericana (University of California Press, I94r), págs. 219-226.

357. Obligado, Pedto Miguel, "La vida y la obra de Leopoldo Lugones", en Leopoldo Lugones, Obras poéticas completas [Ver Núm. $58]$.

—, "Leopoldo Lugones", Nac., 26 de marzo de 1943.

358. Olivari, Marcelo, Leopoldo Lugone's (Buenos Aires: Edición "Saeta", Imprenta López, 1940).

359. Onís, Federico de, Antologia de la poesía española e bispranoamericana (Madrid: Publicaciones de la Revista de Filología Española, 1934), págs. 369-396; España ent América (Ediciones de la Universidad de Puerto Rico, T955), págs. 220-222.

_- Anthologie de la poésie ibéro-dméricaine. Introduction et notes de Federico de Onís. Presentación de Ventura García Calderón (Paris: Editions Nagel [Collection Unesco d'oeuvres représentatives], 1956), págs. I84-I88 y 342-343.

360. Oria, José A., "Lugones periodista", Nos. [cit. en I], págs. 305307.

36r. Oribe, Emilio, "Nota sabre Herrera y Reissig-Lugones", Hiperion (Montevideo), Núm. 73, 1942, págs. ז7-20.

362. Oriz, Lucilo, "Lugones y los críticos", Bibliograma (Buenos Aires), Núm. I6, septiembre-octubre de 1956, págs. I8-2I [Sobre los libros de Ara, Borges y Ghiano].

363. Ortiz Vargas, Alfredo, "The poetry of Leopoldo Lugones", $B P A U$., Vol. LXV, diciembre de 1931, págs. I245-1255.

364. Ory, Eduardo de, "Lugones", en Los mejores poetas de la Argentina. Prólogo de Manuel Ugarte (Madrid: Compañía Iberoamericana de Publicaciones, S. A., I928), págs. 195-205.

365. Osmil, Luis Enrique, "El refugio de Lugones", Diario del Plata, I5 de enero de I923. 
366. Osorio, Luis Enrique, "Los grandes de América" [Sobre el odio de Lugones a la política. Su teoría estética; juicios sobre Darío, Nervo y Valencia], Rep. Amer., V, págs. I99-20I [Tomado de Cromo, Bogotá, Colombia].

367. Osorio, Raúl P., "Leopoldo Lugones", $C_{y} C$., 2 I de mayo de rg2r.

\section{$\mathbf{P}$}

368. Pagano, José León, El parnaso argentino. Poesías selectas. Coleccionadas por... (Barcelona-Buenos Aires: Casa Editorial Maucci, s. f. [¿I904?], págs. 227-240.

369. Palacio, Ennesto, "Crítica literaria: Poemas solitarios [sic], por Leopoldo Lugones", Crit., 3 I de enero de I929.

- - "Lugones vivo", Sexto continente (Buenas Aires), Núm. 2, agosto-septiembre de 1949.

370. Panero, Leopoldo, Antología de la poesía hispanomericana desde sus comienzos (Madrid: Editora Nacional, T. I, I944; T. II, r945), págs. I32-I6I.

37 I. Pardo, José, "Leopoldo Lugones", en "Perfiles", Rev. N. de L., II, págs. 383-384; Coj. Ilust., VI, pág. 682.

372. Parker, William Belmont (Editor), Angentines of To-Day (New York: Hispanic Society of America, I920), Vol. II, págs. 903907.

373. Paz, Octavio [Ver Núm. 287].

374. Pedro, Valentín de, Nuevo parnaso argentino. Selección, prólogo y notas de ... (Barcelona: Casa Editorial Maucci, s. f. [i1927?]), págs. 9-25.

375. Pereira Rodríguez, José, "La poesía de Leopoldo Lugones", Nac., 8 de octubre de 1923.

-_, "El caso Lugones-Herrera y Reissig", Repp. Amer., XI, I925, págs. IO-II; Nos. [cit. en I], pp. 250-265 [Hay un folleto de este trabajo ¿de I9I2?].

-_, [Véase Núm. II8].

—. "Influencia de Lugones en la transformación de Julio Herrera y Reissig", Hog., I937 [i?]. 
376. Pérez Petit, Víctor, "El pleito Lugones-Herrera y Reissig", Nos. [citado en I], págs. 227-244.

377. Pérez-Valiente de Moctezuma, Antonio, "A Leopoldo Lugones...", Nac., I9 de febrero de I939.

378. Peyret, B. L., Antologia patriótica. Prosa y verso. Contribución a la enseñanza patriótica de la escuela argentina (Buenos Aires: Librería Nacional de J. Lajouane y Cía., I9II).

379. Phillips, Allen W., "Notas sobre una afinidad poética: Jules Laforgue y el Lugones del Lunario sentimental", Rev. Iber., Vol. XXIII, Núm. 45, enero-junio de 1958, págs. 43-64 [Hay sobretiro].

—_, "La prosa artística de Leopoldo Lugones en La guerra gaucha", $L_{a} T$., Año V, Núm. I7, enero-marzo de I957, págs. I6r-I98.

- $[$ [Reseña de los libros de Borges y Ghiano sobre Lugones], NRFH., X, págs. 449-454.

380. Piccirilli, Ricardo; Romay, Francisco L., y Gianello, Leoncio, Diccionario histórico argentino (Buenos Aires: Ediciones históricas argentinas, I954), T. IV, págs. 877-880.

38I. Picón Salas, Mariano, "Para una interpretación de Leopoldo Lugones. Modernismo y argentinismo", Nac., I de septiembre de I946.

—., "Para una interpretación de Lugones", RNC., Núm. 59, noviembre-diciembre de 1956 , págs. 29-42.

382. Pillement, Georges, Les conteurs bispano-américains (Paris: Librairie Delagrave, I933), págs. I0-II y 99-104.

383. Pimentel, Francisco, "Nada en serio" [Sobre la omisión del nombre de Lugones en la lista de los diez hombres más famosos de Argentina], Coj. Ilust., XXI, págs. 563-564.

384. Pinto, Juan, Panorama de la literatura argentina contemporanea (Buenos Aires: Editorial Mundi, 194I), págs. 229-236.

—, Breviario de la literatura argentina contemporáned (Buenos Aires: Editorial "La Mandrágora", I958), págs. I39-I4T y otras.

-_.-, "Leopoldo Lugones y la Biblioteca Nacional de Maestros", Hog., Núm. 27, I7 de junio de I955. 
385. Plácido, A. D., "Leopoldo Lugones. Su formación, su espíritu y su obra", RIHIGU., T. XVII, I943, págs. 7-25 [Hay separata con el siguiente pie de imprenta: "Montevideo: Imprenta "El Siglo Ilustrado", I943].

386. Poetas y bufones. Polémica Vasconcelos-Cbocano... Lugones (Madrid: s. f. ni pie de imprenta), 200 págs.

387. Portuondo, José Antonio, "Leopoldo Lugones y Gabrielle D'Annunzio", Literatura (La Habana, Cuba), I, Núm. 2, I938, págs. I23-I 25.

388. Pardos, Emilio [Ver Núm. 287].

389. Prampolini, Santiago, Historia universal de la literatura (Buenos Aires: Uthea Argentina, I94I), T. XII, págs. 505-507.

390. Prins, E., "Lugones, poeta de vanguardia", Vid. Lit., I I de junio de r929.

39I. Puccini, Mario, "Lugones, grande poeta argentino", Le lettere (Roma), 25 de julio de 1938.

392. Puig, Juan de la Cruz, Antología de poetas argentinos (Buenos Aires: Editores: Martín Biedma e Hijo, r910), T. X, págs. XXXVII-XXXIX y 383-432.

393. Pultera (h), Raúl, Lugones. Elementos cardinales destinados a determinar una biografía (Buenos Aires: sin pie de imprenta, I956).

\section{Q}

394. Quiroga, Horacio, "Leopoldo Lugones", Tr., 2 I de agosto de I905.

—, "El caso Lugones-Hertera y Reissig", Hog., I7 de julio de 1925; Rep. Amer., XI, 1925, págs. 9-10.

- [ [Ver también Núm. II8].

395. Quirós Mouzo, Servio, Figuras de la literatura argentina (San tiago de Chile: Nascimento, I942), págs. 37-42.

\section{$\mathbf{R}$}

396. Ramos, Juan P.,., "Leopoldo Lugones", Nos. [cit. en I], págs. I8-26.

397. Reyes, Alfonso, "Leopoldo Lugones", El Nacional (México), 27 de febrero de 1938; Nos. [cit. en I], págs. 344-345; Pasado inmediato y otros ensayos (México, I94 ), págs. 86-87; Obras com- 
pletas (México: Fondo de Cultura Económica, I96I), T. XII, págs. $x_{47-I 49}$ y 267.

398. Roca, Deodoro, "Leopoldo Lugones" en El difícil tiempo nuevo Selección, prólogo y notas de Gregorio Bergman. Epílogo de Enrique González Tuñón (Buenos Aires: Editorial Lautaro [Colección El Pensamiento Argentino, 2], I956.

399. Roca Franquesa, José María [Ver Núm. r95].

400. Rohde, Jorge Max, Las ideas estéticas en la literatura argentina (Buenos Aires: Edición Coni, I92I), T. I, págs. 289-300.

40I. Rojas, Ricardo, "Carta de Ricardo Rojas", Nos. [cit. en I], págs. 319-32I.

- Historia de la literatura argentina. Los modernos (Buenos Aires: Editorial Losada, S. A., I949), págs. 638-639.

402. Rojas Paz, Pablo, "Las industrias de Atenas", Not., V, I2 de septiembre de I9r9.

—-, "La torre de Casandra", Not., 24 de septiembre de igr9.

—, "Filosofícula, por Leopoldo Lugones", Mar. F., Núm. 7, 25 de julio de I924.

—- "Leopoldo Lugones", Sustancia (Tucumán, Argentina), Año I, Núm. 2, septiembre de 1939, págs. I78-183.

403. Rolla, Matilde, Disegno storico della litteratura argentina (Roma: Editrice Studium, I932).

404. Romagosa, Carlos, Joyas poéticas americanas. Colección de poesias escogidas originales de autores nacidos en América (Córdoba, Argentina: A. Aveta, 1897).

- Labor literaria (Córdoba, 1898).

—, Vibraciones fugaces (Córdoba, 1903).

- y Mariano de Vedia, "Lugones llega a Buenos Aires", Nos. [cit. en I], págs. Ir-I6 ["Carta de Romagosa a Mariano de Vedia, en págs. I2-16].

405. Rosales, César, "De Las montañas del oro a las Odas seculares", Nac., 29 de enero de I96r.

406. Ruiz, Luis Alberto, Diccionario de la literatura universal (Buenos Aires: Editorial Raigal, 1956), T. II, págs. 150-152.

$\mathrm{S}$

407. Sáinz de Robles, Federico Carlos, Ensayo de un diccionario de la literatura (Madrid: Aguilar, 1949), Vol. II, págs. 928-929. 
408. Sánchez, Luis Alberto, "Lugones, adalid y gregario", Nos., [cit. en I], págs. 58-63; ND., Año XIX, Núm. 6, I938, págs. 9-io y $3 \mathrm{I}-32$.

-, Nueva historia de la literatura americana (Asunción, Paraguay, 1950), págs. 399-400.

409. Sánchez Trincado, José Luis, "Leopoldo Lugones ante la nueva literatura", en Stendhal y otras figuras (Buenos Aires: Imprenta López, I943), págs. 53-62.

4ro. Sanín Cano, Baldomero, "Kodak argentino", Nac., I2 de junio de 1927.

- -, "Lugones ha muerto", El tiempo (Bogotá, Colombia), 27 de febrero de 1938; Nos. [cit, en I], págs. 337-343.

—_, "La actitud de Lugones" [Réplica: Defensa de Lugones a propósito de un artículo de José Gabriel; véase Núm. 223], Rep. Amer., VII, I923, pág. 87 [Tomado de España].

4Ir. San Martín, José de, Mis profetas locos (Buenos Aires: N. Tommassini, 1909; 2da. ed.: Arnaldo Moen, editor, I918).

4I2. Santillán, Diego A., Gran Enciclopedia Argentina (Buenos Aires: Ediar, I956), T. IV (x958), págs. 484-485.

4I3. Saz, Agustín del, Resumen de historia de la novela bispianoamericana (Barcelona: Editorial Atlántida, S. A., I949), pág. 82.

—_, La poesía hispanoamericana (Barcelona: Editorial Seix Barral, S. A. [Colección Estudio de Conocimientos Generales, 6], I948), págs. II4-II9.

—, En Díaz Plaja, Guillermo, Historia general de las literaturas bispánicas (Madrid; Vol. IV, Segunda Parte, págs. 586-588.

4I.4. Segalá y Estalella, Luis, "Letras clásicas" [Carta a Lugones, firmada en Barcelona, I de junio de 1926 en la que le solicita una bibliografía de las traducciones de Hometo hechas en Hispanoamérica], Rep. Amer., XIII, I926, pág. 302.

4I5. Selva, Juan B., "Ld guerra gaucha, de Lugones: su estructura léxica", BRAE., XXXIV, I954, págs. 257-26I.

416. Semprún, Jesús, "A propósito de los nuevos versos de Leopoldo Lugones", ["Elogio de 'Los burritos" "], Coj. Ilust., XVII, pág. 519.

—, "Leopoldo Lugones, 'El himno a la luna'", Rev. Mod., XI, págs.. I 22-I 23 . 
417. Seoane, Manuel A., "Al señor Leopoldo Lugones" [Carta abierta], Nac., 2 I de abril de I925.

4r8. Shipley, Joseph T., Encyclopedia of Literature (New York: Philosophical Library, r946), Vol. II, pág. 9ro.

419. Soboloesky, Marcos, "Aseveración sobre Lugones", Nac., I6 de febrero de 1958.

420. Soiza Reilly, Juan J., "Leopoldo Lugones", Hog., 3I de julio de I925.

421. Solar Correa, Eduardo, Poelas bispanoamericanos. Selección y notas de... (Santiago de Chile: Imprenta Cervantes, I926), págs. I62-I70.

42.2. Sosa López, Emilio, "Tendencia de la poesía argentina actual", Realidad (Buenos Aires), Vol. 5, Núm. I3, enero-febrero de I949, págs. 73-80 [Sobre Lugones, págs. 75-76].

423. Soto, Luis Emilio, "Leopoldo Lugones: Las fuerzas extrañas", en Critica y estimación (Buenos Aires: Sur, 1938), págs. I39-I4I. -, "Advenimiento de Lugones", Nac., 22 de febrero de 'T948; Rep. Amer., 30 de julio de 1948.

—, "Sobre algunos cuentos de Lugones", Nac., 8 de marzo de 1956.

- En Arrieta, Rafael Alberto, Historia de la literatura argentina (Buenos Aires: Ediciones Peuser, I959), T. IV, págs. $330-336$ y $397-398$.

—, "Leopoldo Lugones, en Diccionario de la literatura latinoamericana. Argentina. Primera Parte (Washington: Unión Panamericana, I960), págs. II7-124.

424. Speratti Piñero, Emma Susana, "La expresión de Las fuerzas extrañas en Leopoldo Lugones", UM., IX, Núm. 7, I955, págs. I9-2I.

-y Barrenechea, Ana María, La literatura fantástica en Argentina (México: Imprenta Universitaria, 1957), págs. r-r6.

425. Stivers, William, A Study of the Poetic Works of Leopoldo Lugones (Tesis doctoral: University of Southern California, I95I).

426. Storni, Alfonsina, "Alrededor de la muerte de Lugones", Nos. [cit. en I], págs. 2I8-22r.

427. Suárez Calimano, Emilio, "Orientaciones de la literatura hispanoamericana de los últimos veinte años", Nos., Año XXI, T. 57 , 
Número Extraordinario, agosto de 1927, págs. 285-314 [Véase también Núm. 2rI].

428. Tablada, José Juan, "Leopoldo Lugones: Las montañas del oro", Rev. Mod., I, I8-20, 33-36, 50-52 y 68-69; Coj., Ilust., VII, pág. 528.

429. Tagle, Armando, "Lugones", en Estudios de psicología y de critica (Buenos Aires: Talleres Gráficos Capellano Hnos., x933), Vol. I.

—- "Leopoldo Lugones. Le poète" [Traducción al francés de M. Gahisto], Rev. Arg., II, Núm. 15, marzo-abril de 1936, págs. $3^{\mathrm{I}-40}$.

430. Talamon, C. O., "Leopoldo Lugones y el folklorismo", revista Azul (Azul, Buenos Aires), Año II, Núm. Io, junio de I93r, págs. $178-183$.

43'. Tailhade, Laurent, "Los reflejos de París" [Traducción del francés: reflejos de París y la lengua francesa sobre Lugones, etc.], Coj. Ilust., XII, págs. 512-5I3.

432. Tejera, H., "Maestro Lugones", Nac., 27 de diciembre de 1939.

433. Tentori, Francesco, Poesía ispano-americana del 900 (Parma, Italia: Guanda Editore [Collana Fenice N. 34], 1957), págs. IroI 25 y $462-463$.

434. Terán, Juan B., "El imperio jesuitico, por Leopoldo Lugones", Estudios y notas (Tucumán, I908), págs. 95-121.

435. Testena, Folco, "Lugones, poeta pagano", Nos. [cit. en I], págs. 87-94.

-, "Nostalgias de Buenos Aires. Leyendo un número extraordinario de Nosotros", Nos., Segunda Epoca, Año III, T. 8, Núm. 3I, octubre de 1938, págs. 343-353 [Sobre Lugones, págs. 35I-352].

_-, Antologia della poesia argentina moderna [Versión italiana de la primera edición de la de Noé] (Milaso, Alpes, Casa Editrice, 1927).

- Poeti argentini. Tradotti all'italiano da... Introduzione di Julio Noé (Buenos Aires: Librería Editorial Attilio Muro, r398). 
436. The Encyclopedia Americand (New York-Chicago-Washington, D. C.: Americana Corporation, 1959), Vol. XVII, pág. 34 [Artículo de Arturo Torres Ríoseco].

437. Thomas, Kathleen Hickey, Modernismo in Poetry and Its Expo. nents: Manuel Gutiérrez Nájera, Rubén Dario and Leopoldo Lugones (Tesis doctoral: University of Pittsburgh, I96I).

438. Tild, J., "Sobre Lunario sentimental", RAL., XIII, 1927, págs. $464-465$.

439. Toro y Gisbert, Miguel de, "El idioma de un argentino: La guera gaucha", BRAE., Año IX, T. IX, I922, págs. 526-548 y 705728.

440. Torre, El Charrúa de la, "Carta abierta a Leopoldo Lugones", Crítica (Buenos Aires), 12 de julio de 1923.

44I. Torre, Guillermo de, "El pleito Lugones-Herrera y Reissig", Arg.L., I2 de marzo de I942; La civentura y el orden (Buenos Aires: Editorial Losada, S. A., I943), págs. 'I8I-220, 2da. ed., Idem., págs. 202-210 [Forma parte del "Estudio preliminar" a las Poesias completas de Julio Herrera y Reissig (Buenos Aires: Editorial Losada, S. A., I942; 2da. edición, r945), págs. 2I-29.

442. Torrendell, Juan, El año literario. Prólogo de Constancio C. Vigil (Buenos Aires: Editorial Tor, s. f. [¿rgrg?] [Sobre El libro de los paisajes] [No lo he visto].

- Crítica menor (Lugones), II (Buenos Aires: Editorial Tor, 1934) [No lo he visto].

443. Torres Bodet, Jaime, "El defraudador defraudado o el retórico sofista", Rep. Amer., XV, pág. 368; Contemporáneos. Notas de crítica (México: Herrero, I928).

444. Torres Ríoseco, Arturo, "El Modernismo y la crítica", Nos., Año XXIII, T. 65, Núms. 243-244, agosto y septiembre de r929, págs. 320-327.

-- Antología de la literatura bispanoamericana (New York:

F. S. Crofts and Co., I939), pág. I9r.

—, La gran literatura iberoamericana (Buenos Aires: Emecé Editores, 1945), págs. I29-13I; Nueva bistoria de la gran literatura iberoamericana (Buenos Aires: Emecé Editores, 1960), págs. Ir6-II7. 
- The Epic of Latin American Literature (University of California Press, I959), págs. II3-II4.

—, The Encyclopedia Americana [Ver. Núm. 436].

445. Trazar, Ricardo F., "Recordando el lar nativo de Leopoldo Lugones", LaPr., 22 de septiembre de 1957.

446. Treccani [Ver Diccionarios, Núm. 192].

447. Trigo Viera, Manuel, "Leopoldo Lugones en la cátedra de estética", Nac., 7 de marzo de 1943.

448. Turner, Charles Louis Joseph, Leopoldo Lugones: His Interpretation of the Argentine Republic (M. A. Thesis: Columbia University, 'i936).

\section{$\mathrm{U}$}

449. Ugarte, Manuel, La joven literatura bispanoamericana. Antología de prosistas y poetas (París: Armand Colin, r.906; 2da. ed., I9I2; 3ra. ed., r9I5; 4 ta. ed., r9I9), págs. I64-167.

-, "Leopoldo Lugones", Nos. [cit. en I], págs. 5I-52.

- Escritores iberoamericanos de I900 (Santiago de Chile: Editorial Orbe, I943), págs. I6I-I74; 2da. ed., México: Editorial Vértice, 1947), págs 163-173.

450. Uriarte, Gregorio, "La obra intelectual de Lugones", Nos., Año XII, T. 30, Núm. II6, diciembre de 1918, págs. 530-563; En inglés: "The Intelectual Work of Leopoldo Lugones", Int. Amer., Vol. 2 Núm. 6, August, I9I9, págs. 368-386.

45I. Valdaspe, Tristán, Historia de la literatura argentina e bispanoame. ricana. Con numerosos trozos selectos (Buenos Aires: Moly y Lasserre, Editores; 3ra. edición, I937), págs. 219-220.

452. Valenzuela, E., "Leopoldo Lugones, Lunario sentimental", Rev. Mad. XII, págs. I9I-I92; XIII, págs. 259-26r.

453. Valldeperes, M., "Evocaciones. Lugones, poeta de la exaltación patriótica", Romance (México), I, Núm. II, I940, pág. 6.

454. Varela Avellaneda, C., "Leopoldo Lugones: Antología poética", Sustancia (Tucumán), II, I94I, págs. 7I2-7I4. 
455. Vasconcelos, José [y otros], "Homenaje a Lugones, con motivo de la segunda edición de Los crepúsculos del jardin", Rep. Amer., XIII, I926, págs. I64-I67.

— [Ver también Núm. i 8 y Núm. 386].

456. Vázquez Cañas, Juan, Leopoldo Lugones y el zodiaco lugoniano (Buenos Aires: Edición Ateneo Ibero-Americano, S. A., [1940], 45 págs.

457. Vedia, Joaquín de, Como lo vi yo (Buenos Aires: Edición $M$. Gleizer, I922).

458. Vedia, Mariano de [Véase Núm. 404], "A vuelo de pluma", Raz., 22 de junio de 1924.

459. Vela, Arqueles, "Lugones: Interludio decadente", en Teoria literaria del modernismo. Su filosofia. Su estética. Su técnica (México: Ediciones Botas, I949), págs. 218-225.

460. Vélez, Juan José, Discursos y conferencias (Córdoba, Argentina: Editorial Pereyra, I929), Pp. I37-164 (Sobre El libro de los paisajes].

46r. Vera, Humberto B., Evocación lírica de Leopoldo Lugones (La Plata, Argentina: Talleres Gráficos Olivieri y Domínguez, I940), 35 págs.

462. Vian, Francesco, Il "modernismo" nella poesia ispanica (Milano:

La Goliardica. Edizioni Universitarie, 1955), págs. 218-229.

463. Vidal Ferreyra, Videla [Ver Ferrari Nicolay, Mauricio].

464. Vidal Peña, Leónidas, "La personalidad de Lugones", Nos. [cit. en I], págs. I57-I6r.

_., El drama intelectual de Lugones. Ensayo sabre su personalidad y su obra (Buenos Aires: La Facultad, I938).

465. Vignale, Pedro Juan y César Tiempo, Exposición de la actual poesía argentina (I922-1927) (Buenos Aires: Editorial Minerva, I927) [Contiene "Situación del lector", por Leopoldo Lugones, págs. I-II].

466. Vignatti, Milciades, "Lugones, hombre de ciencia", Tribuna universitaria (Buenos Aires), Año III, Núm. 24, I5 de octubre de rgi6. 
467. Villafañe, Raúl J., [Véase Carreño, Carlos A., Núm. 158].

468. Villalobos Domínguez, Carlos, "Las ideas regresivas de Lugones", Nos., Año XIX, T. 50, Núm. 194, julio de 1925, págs. 361-383. —, "La Grande Argentina, por Leopoldo Lugones", Nos., Año XXIV, T. 70, Núm. 257, octubre de 1930, págs. 122-124.

469. Villaurrutia, Xavier [Ver Núm. 287].

470. Viñas, David, "Leopoldo Lugones. Mecanismo, contorno y destino", Centro (Buenos Aires), Año III, Núm. 5, I953, págs. 3-22.

47x. Vitis, Juan Vicente de, Florilegio del parnaso americano. Prólogo de Juan Vicente Ramírez (Barcelona: Casa Editorial Maucci, s. f.), págs. $43-48$.

\section{W}

472. Walsh, Thomas, Hispanic Antbology (New Ylork: London: G. P. Putman's Sons., I920), págs. 664-669.

473. Weisinger, Nina Lee, $A$ Guide to Studies in Spanish American Literature (Boston-New York, etc.: D. C. Heath and Co., 1940), pág. 46.

474. Wyld Ospina, Oscar, "Nuevas respuestas al cuestionario del Repertorio Americano [Defensa de Lugones ante un ataque publicado por Moisés Vincenzi en Caracteres americanos; cita Leavitt. No la he visto].

\section{Y}

475. Yunque, Alvaro, Sintesis bistórica de la literatura argentina (Buenos Aires: Editorial Claridad, I957), págs. I45-T48.

- y Zarrilli, Humberto, La moderna poesía rioplatense (Buenos Aires: Editorial Futuro [Colección Eurindia], I944), págs. 28-29.

\section{Z}

476. Zarrilli, Humberto [Ver Núm. 475].

477. Zía, Lizardo, "Semblanzas. Leopoldo Lugones", Vid. Lit., Núm. I, I923. 
478. Zingone, Nelva E., "La celebración poética del Centenario de Mayo: Lugones y Banchs", en Algunos aspectos de la cultura literaria de Mayo (Universidad Nacional de La Plata, Argentina. Departamento de Letras, I96I), págs. 2II-232.

479. Zocchi, Juan, "Pasión de Lugones", Nos., [cit. en I], págs. I82I94.

480. Zorrilla de San Martín, S. J., Juan C., Historia de la literatura y antología escolar hispanoamericana (Santiago de Chile: Nascimento, I93 I), T. II, págs. 340-34I.

481. Zum Felde, Alberto, "Una novela oculista de Lugones", El dia (Montevideo), 2 de junio de 1926.

—, "Lugones ante la posteridad", Nos. [cit. en r], págs. I42r49.

_, "El 'formidable' Lugones", Nac., I I de marzo de 1962.

\section{SIGLAS CORRESPONDIENTES A LA BIBLIOGRAFIA}

AHond.-Ateneo de Honduras. Tegucigalpa, Honduras.

Arg.L.-Argentina libre. Buenos Aires, Argentina.

Atenea.--Revista Atenea. Universidad de Concepción, Chile.

$B A A L$ - Boletín de la Academia Argentina de Letras. Buenos Aires.

BANH.-Boletín de la Academia Nacional de la Historia. Buenos Aires.

Babel.-Revista Babel. Buenos Aires.

BET.-Boletín de Estudios del Teatro. Buenos Aires.

Bibl.-La biblioteca. Buenos Aires.

$B P A U$-Bulletin of the Pan American Union. Washington, USA.

BRAE.-Boletin de la Real Academia Espiañola. Madrid, España.

CCLA.-Cuademos del Congreso por la Iibertad de la Cultura. París.

Coj. Ilust.-El cojo ilustrado. Caracas, Venezuela.

Com.-Revista Comentario. Buenos Aires.

Crit.-Revista Criterio. Buenos Aires.

Cur. Conf.-Cursos y conferencias. Buenos Aires,

CuVen.-Cultura venezolana. Caracas.

CyC.-Caras y caretas. Buenos Aires.

Dav.-Revista Davar. Buenos Aires.

DEsp.-El diario español. Buenos Aires.

EALP.-Estudios de la Academia Literaria del Plata. Buenos Aires. 
Esp. Hab.-El espactador babanero. La Habana, Cuba.

Fic.-Revista Ficción. Buenos Aires.

Fr. Amer-France-Amérique. Revue Mensuelle du Comité France-Amérique.

Gac. Lit.-Gaceta literaria. Buenos Aires.

Gac. Lit. M.-La gaceta literaria. Madrid.

Hist.-Histonium. Buenos Aires.

Hog.-El bogar. Buenos Aires.

HuT. Humanitas,-Revista de la Facultad de Filosofía y Letras. Universidad Nacional de Tucumán, Argentina.

Ideas.-Revista Ideas. Buenos Aires.

Inic.--Revista Inicial. Buenos Aires.

Inter. Amer.-Revista Inter-America. New York.

LaPr.-Diario La Prensa. Buenos Aires.

LaT.-Revista La torre. Universidad de Puerto Rico. San Juan, Puerto Rico.

Mar. F.-Revista Martin Fierro. Buenos Aires.

Mer.-Diario El mercurio. Santiago, Chile.

Mer. Am.-El mercurio de América. Buenos Aires.

MM.-Mundial magazine. Buenos Aires.

Mov.-Periódica Movimiento. Buenos Aires.

MPh.-Modern Pbilology. Chicago, USA.

Nac.-Diario La nación. Buenos Aires.

ND.--Revista La nueva democracia. New York.

NL.-Les nouvelles littéraives. París.

Nos.-Levista Nosotros. Buenos Aires.

Not.-Periódico La nota. Buenos Aires.

NRFH.-Nueva revista de filología bispánica. México.

OyO.-Oriente y occidente. Buenos Aires.

Pal.-La palabra. Córdoba, Argentina.

P. U.-Plus ultra. Buenos Aires.

RAL.-Revue de l'Amérique Latine. París.

Raz.-Diario La razón. Buenos Aires.

Rep. Amer-Repertorio americano. San José, Costa Rica.

Rev. Am. L La revista de América. Buenos Aires.

Rev. Arg.-Revue argentine. París.

Rev. Cu.-Revista cubana. La Habana, Cuba.

Rev. Iber.-Revista iberoamericana. Organo del Instituto Internacional de Literatura Iberoamericana. USA. 
Rev. Ind.-Revista de las Indias. Bogotá, Colombia.

Rev. Inst. Parag.-Revista del Instituto Paraguayo. Asunción, Paraguay.

Rev. Mod.-Revista modema de México. México.

Rev. Nac.-Revista nacional. Montevideo, Uruguay.

Rev. Nac. Lit.-Revista nacional de literatura y ciencias sociales. Montevideo, Uruguay.

Rev. Soc.--Revista socialista. Buenos Aires.

Rev. Univ. Hond.--Revista de la Universidad de Honduras. Tegucigalpa.

RHC.-Revista Humanidades. Universidad Nacional de Córdoba. Argentina.

RIHGU.--Revista del Instituto de Historia y Geografía del Unuguay.

Montevideo, Uruguay.

RNC.-Revista nacional de cultura. Catacas, Venezuela.

RUBA.-Revista de la Universidad de Buenos Aires. Buenos Aires.

RUNC.-Revista de la Universidad Nacional de Córdoba. Argentina.

TPr.-Tiempo presente. Buenos Aires.

Tr.-Tribuna. Buenos Aires.

UM.-Revista de la Universidad de México. México.

$V$ ang.-Periódico La vanguardict. Buenos Aires.

Vid. Hoy. Vida de Hoy. Buenos Aires.

Vid. Lit.-La vida literaria. Buenos Aires. 
